\title{
Australia's National Electricity Market - optimising policy to facilitate demand-side response
}

In this article, we outline the recent reductions in electricity sector capital productivity and higher end use prices. Unsurprisingly, policy makers are now examining ways to encourage greater levels of consumer participation to improve capacity utilisation and outcomes for consumers. We find that consumers are likely to be better off by responding to retail, rather than wholesale generation pricing. Retail prices reflect potential savings across all supply chain costs including the primary driver of recent price increases, capital-intensive networks. Conversely, the wholesale electricity generation market is currently heavily oversupplied and savings for consumers are likely to be scarce.

Keywords: demand-response; energy-only markets; microeconomic reform JEL Codes: D04, D47, Q40, Q41, Q48

\section{Introduction}

The economic productivity of Australia's electricity system has come under scrutiny in recent years. Significant increases in retail prices have accompanied reductions in underlying electricity demand and a proliferation of distributed generation technologies. Simshauser and Nelson (2013) found that Australian electricity tariffs rose by 10\% per annum from 2009 to 2013 following real price reductions in the two preceding decades. At the same time, the productive utilisation of the electricity system fell $13 \%$. Consequentially, much of the energy policy discussion is related to the prospect of an 'energy market death spiral' ${ }^{1}$ within Australia's National Electricity Market:

NEM (see Simshauser and Nelson, 2014 or Saddler, 2013 for commentary around recent trends in electricity prices and demand).

\footnotetext{
${ }^{1}$ A 'death spiral' refers to a situation where average cost pricing results in electricity consumers reducing consumption at times of excess capacity in response to higher prices, which results in fixed costs being spread across reduced output, resulting in further reductions in demand at times of excess capacity, and so on. 
Nelson and Orton (2013, p. 7) summarise the nature of electricity supply by stating:

'Electricity is relatively unique among goods and services as it cannot be stored economically. As it is produced, it must be consumed. Inventory management cannot be used to allow for smooth production schedules to meet variable demand. Electricity markets are also characterised by significant demand variability as a result of changes in weather. Space heating and cooling requirements can result in rapid increases in demand for small periods on the coolest and hottest days respectively.'

This means that there must be sufficient generating capacity to meet peak period demand, but much of this will be unused in periods of low demand. In the absence of sound policies to encourage consumers to use electricity in off peak periods, there will be a low utilisation rate of installed capacity. Good policies will involve pricing signals: lower prices to encourage use of electricity in times of low demand and higher prices to discourage consumption in peak periods. Pricing signals can therefore provide the incentive for consumers to utilise capacity efficiently ${ }^{2}$.

Increased costs to consumers in recent years have been primarily caused by expenditure on network capital and a reduction in capacity utilisation due largely to the absence of appropriate pricing signals. In the five years to Financial Year 2015 (FY15), aggregate capital expenditure on east-coast networks is estimated to be $\$ 35.1$ billion. At the same time, capital expenditure on power generation $^{3}$ is estimated to be in the order of $\$ 5.2$ billion. Network tariffs have doubled in some jurisdictions over the five years from 2009. In 2015, wholesale electricity prices in real terms are no higher than they were at the commencement of the NEM sixteen years ago.

\footnotetext{
${ }^{2}$ Greater penetration of intermittent renewable capacity (and possibly battery storage) is likely to add to the importance of efficient pricing within the Australian electricity system.

${ }^{3}$ Renewable generation is not included in this calculation as investment in renewables has been driven by environmental policy (such as the Renewable Energy Target and Feed-in Tariffs) rather than market signals.
} 
In 2012, the Australian Energy Market Commission (AEMC) released a landmark report which has become known as the 'Power of Choice' report. The report contained several recommendations to increase consumer participation in electricity markets with an aim of increasing capital utilisation and productivity. The two most prominent of these recommendations involve introducing a demand response mechanism (DRM) in the wholesale electricity market and the deregulation of electricity metering to establish greater competition and cost-reflective retail pricing signals. While there have been several studies completed on the benefits of introducing cost-reflective network (i.e., 'poles and wires') and retail electricity pricing, there is an absence of literature on the anticipated effectiveness of regulatory interventions that could be undertaken in Australia to facilitate demand-side participation at the wholesale (i.e., electricity generation) market level. This paper therefore asks two simple questions, 'is a market failure preventing demand-side participation in wholesale and/or retail markets and, if so, what is the optimal policy response'? To answer these questions, we contrast our analysis of wholesale market conditions and the DRM concept with the results of previous studies into cost-reflective retail electricity pricing.

This paper is structured as follows: Section 2 provides a brief overview of the history of Australian electricity market microeconomic reform as context to explain some of the challenges facing the energy sector; a brief literature review is presented in Section 3 to categorise policies at the wholesale and retail pricing level; the effectiveness of demand response implemented at the wholesale and retail level is assessed in Section 4; with brief concluding remarks and policy recommendations contained in Section 5. 


\section{History of Australian electricity market reform}

Australia's microeconomic policy agenda in the 1990s led to the structural reform of the electricity and gas industries (see Hilmer, 1993 for the original competition policy recommendations related to structural separation of public monopolies). State Electricity Commissions had historically been responsible for operating electricity systems within jurisdictional boundaries. As a result of the National Competition Policy (NCP) reform process established following the Hilmer Report, these Commissions disaggregated their power generation, transmission grid, distribution network and retail supply functions and in some states these newly created businesses were privatised. The economic policy rationale was simple - the introduction of competition into the parts of the supply chain that facilitated competition and for network businesses, the part of the supply chain exhibiting natural monopoly elements, the use of economic regulation to prevent monopolistic behaviour and pricing. 
The reform of electricity generation and creation of the NEM could be argued to have been the centrepiece of microeconomic reform of the east-coast electricity market. The NEM is an energyonly gross pool electricity market in which prices are formed under a uniform first-price auction clearing mechanism. Put simply, generators are paid for the energy they generate but not the capacity they make available to ensure overall supply is always reliable. The operation of the market is well documented in Simshauser $(2008,2010)$ - prices during 'off-peak' periods tend to reflect short-run marginal costs of power generation, while prices at 'peak' periods can increase by around $25,000 \%$ to over $\$ 13,000$ per megawatt-hour (MWh) - thus providing significant economic opportunities for customers with flexible consumption to 'shift load' from peak to off peak periods. In 2002, the Parer Review estimated that increased annual Gross Domestic Product (GDP) created through the reform process was $\$ 1.5$ billion (Parer, 2002). However, as will be revealed later in this article, significant reform of the wholesale market for electricity was not accompanied by product market reform (i.e. deregulation of retail end-user electricity pricing) and a host of greenhouse-gas policies, such as the Renewable Energy Target and Premium Feedin Tariffs, were overlaid upon the NEM's operation.

Distribution and transmission network companies, or 'poles and wires' businesses as they are often referred to, are regulated monopoly infrastructure investments characterised by relatively stable financial returns on a highly capital-intensive asset stock. These businesses have a vast asset management and maintenance task and a focus on the efficient and reliable (physical) supply of energy to society. Initially, much of the regulation of these businesses was done by jurisdictional pricing regulators operating within state boundaries. However, post implementation of the Australian Energy Market Agreement in 2004, these functions have been gradually transferred to the Australian Energy Regulator (AER) after its creation in 2005. 
The final component of the reformed supply chain is energy retailing. Energy retailers were created as customer-focused marketing businesses, operating within a competitive environment with acute real-time energy commodity market exposures associated with purchasing electricity through the gross energy-only pool NEM. But the introduction of competition was staged through a scheduled timetable to ensure an orderly transition. Competition for large commercial and industrial customers was introduced immediately as many larger businesses had a relatively welldeveloped understanding of energy markets. Competition allowed these electricity consumers to choose a retail product that met their needs. The introduction of 'full retail contestability' (FRC whereby all customers including households could choose their retailer) was then gradually implemented on a jurisdictional basis. In the NEM, this process commenced from the mid-1990s, and was completed in Victoria and New South Wales in 2002, South Australia in 2003, and Queensland in 2007 (esaa, 2008). Pricing deregulation was only implemented after competition had been deemed 'effective' as determined by the Australian Energy Market Commission (AEMC) under the Australian Energy Market Agreement. Table 1 outlines the introduction of full retail competition and pricing deregulation in each NEM jurisdiction.

Table 1: Retail market reform timetable

\begin{tabular}{ccc}
\hline Jurisdiction & FRC $-\begin{array}{c}\text { Residential and Small } \\
\text { Business }\end{array}$ & Price Deregulation \\
\hline QLD & $2007(<100 \mathrm{MWh} \mathrm{pa})$ & $2016 f^{4}$ \\
NSW & $2002(<160 \mathrm{MWh} \mathrm{pa})$ & 2014 \\
VIC & $2002(<160 \mathrm{MWh}$ pa $)$ & 2008 \\
SA & $2003(<160 \mathrm{MWh} \mathrm{pa})$ & 2013 \\
\hline
\end{tabular}

\footnotetext{
${ }^{4}$ Price deregulation has been deferred in Queensland and as such has been forecast to be introduced in 2016. 
So a critical question for policy makers is whether the reform process gradually implemented over the past 15 years has been successful? When assessed purely from a pricing perspective, the Australian east-coast microeconomic reform of the electricity sector has been somewhat of a failure. Figure 1 shows how Australian electricity prices have increased substantially since 2007 when compared with other nations. However, across other criteria it could be argued that the reform process has been successful - for example, greenhouse gas emissions have fallen by around 10\% compared to 2004 levels (Department of Environment, 2014) and reliability standards are high by world standards. Criticism of the microeconomic reform process to date has largely been focused on issues such as privatisation and economic regulation (see Quiggin, 1997; Beder, 2003; Chester, 2006; and Beder, 2012). Quiggin's view (2014, p. 5) is wider as he sums up, 'It is time to admit that the reform process, as a whole, has been a failure' arguing that shortcomings exist across: pricing; reliability; quality; efficient investment; and efficient operation. 
Figure 1: Electricity tariff changes by country 2007-2013

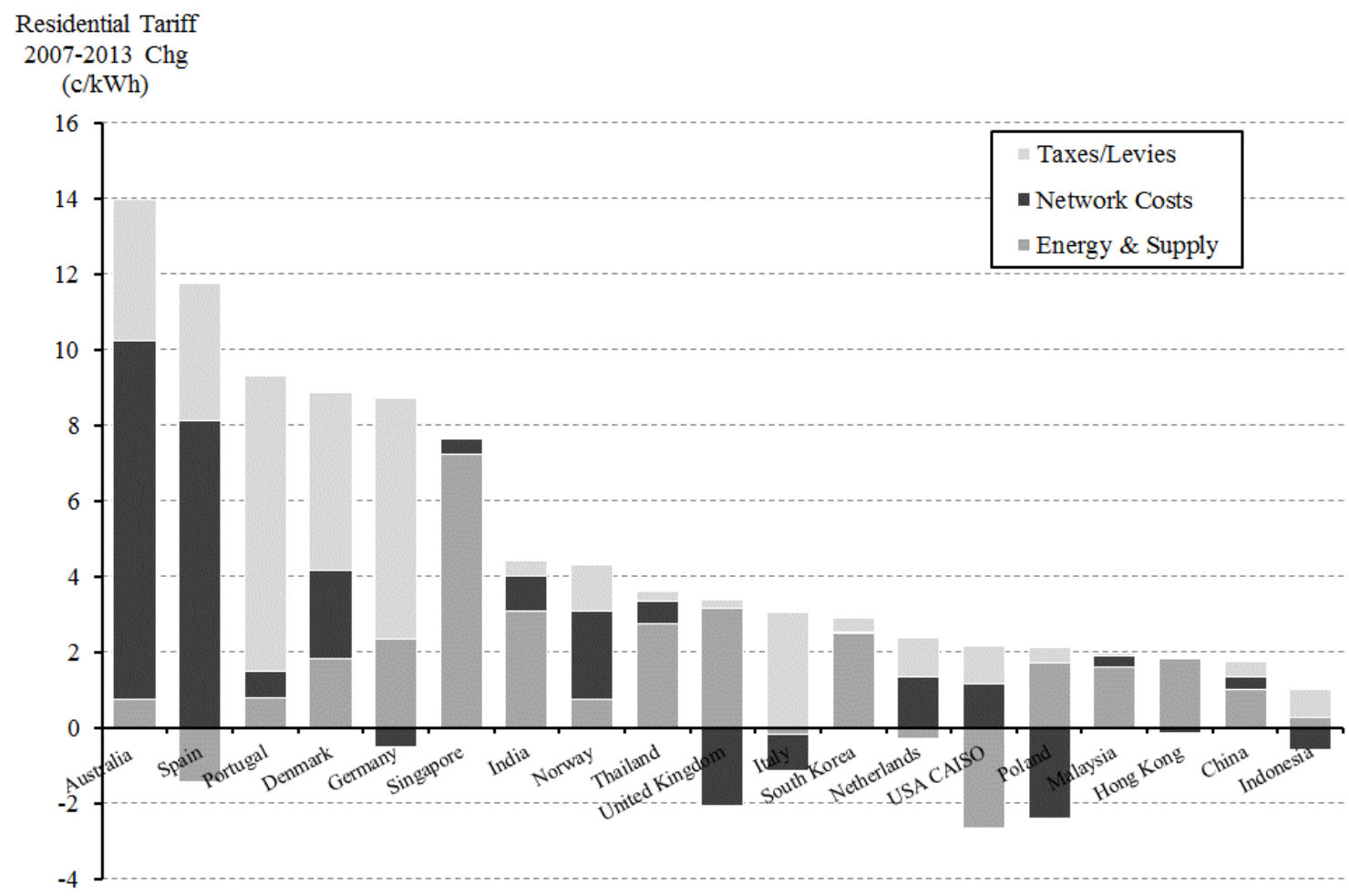

Source: UBS data presented in Simshauser (2014)

Simshauser (2014) explains Figure 1 by stating that Australia has gone from 'first place to last' in relation to international electricity pricing due to a policy-induced 'death spiral' (see below for explanation on the 'death spiral' concept). Quiggin (2014) argues that poor pricing outcomes are related to excessive rates of return on monopolistic assets due to a badly designed regulatory framework. While we would agree with both of these assessments at least in part, in our view it is the failure of policy makers to complete product market reform in a timely fashion that is also responsible for poor retail pricing outcomes. Recall from Table 1 that pricing deregulation was implemented only recently. While prices remained regulated and based upon 'average cost' pricing (prices per unit output), there was a significant decline in load factors driven by materially lower underlying demand growth (or even contraction) while peak demand has increased, driven by the uptake of air-conditioning. This is shown in Table 2 and explains why 'average cost' prices have increased due to reductions in energy throughput while fixed costs have continued to be added to the electricity system to satisfy rising peak demand and increased reliability standards in some jurisdictions (this is the phenomenon known as the 'energy market death spiral'). 
Table 2: Average annual growth in peak and average demand from FY06 to FY14

\begin{tabular}{cccccc}
\hline & NSW & QLD & SA & VIC & TAS \\
\hline Peak Demand & $-0.6 \%$ & $2.1 \%$ & $1.8 \%$ & $2.2 \%$ & $-0.4 \%$ \\
Average Demand & $-0.8 \%$ & $0.1 \%$ & $-0.4 \%$ & $-0.5 \%$ & $-1.4 \%$ \\
\hline \multicolumn{7}{c}{ Source: esaa }
\end{tabular}

The consequence of the 'death spiral' for household electricity prices is demonstrated in Figure 2 which shows electricity costs for an average household from three studies published in 2002, 2011 (based upon 2009 data) and 2014, and the system capacity utilisation estimated in each year. Figure 2 shows that the proportion of the electricity bill related to network costs has increased substantially as reduced throughput in a higher fixed cost system manifests in regulatory outcomes of higher network tariffs and material increases in end-user prices.

\footnotetext{
${ }^{5}$ The timeframe selected for presentation of this data reflects the period in which air-conditioning uptake accelerated, driving increases in localised network peak demand. 
Figure 2: Breakdown of industry components of household electricity costs

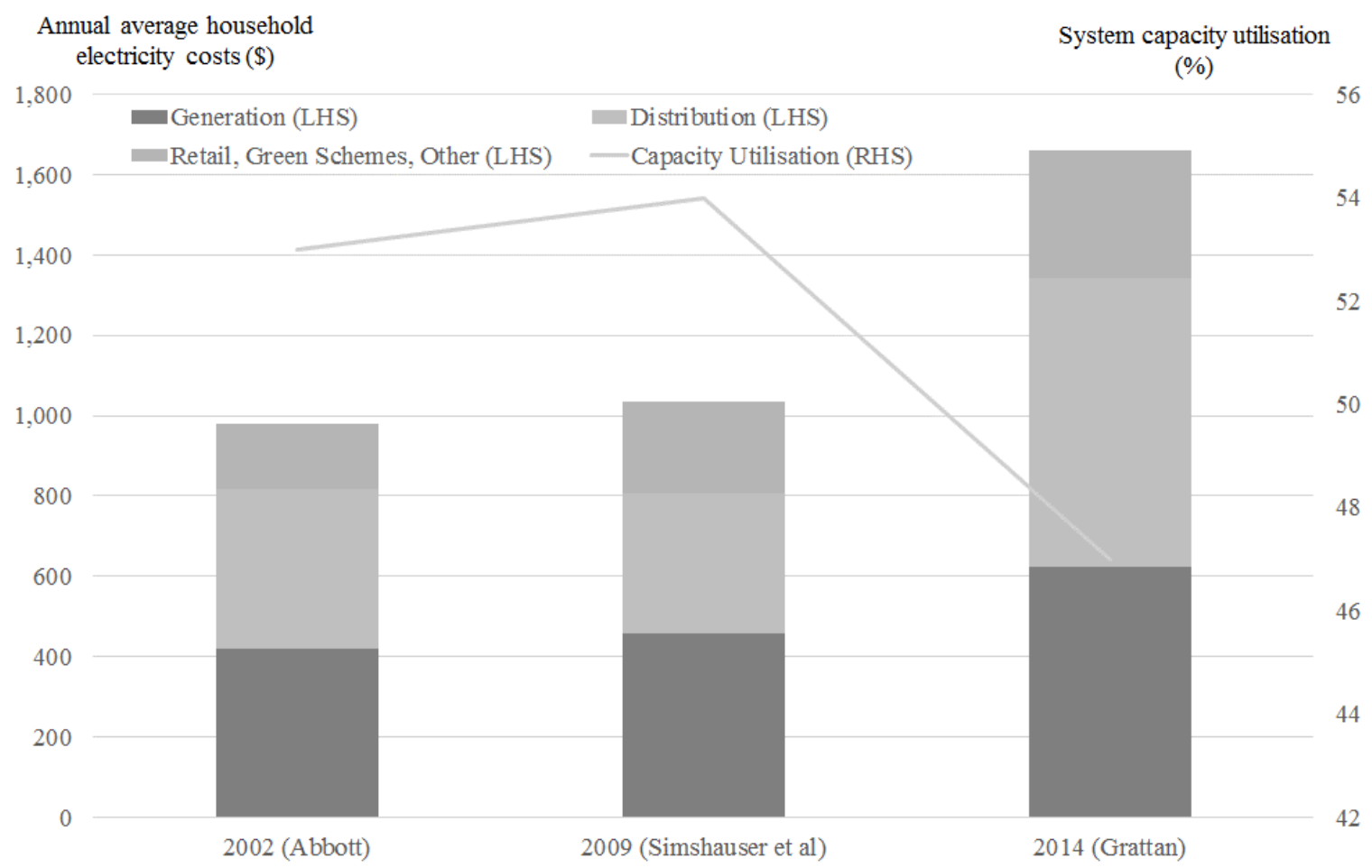

Source: Abbott (2002), Simshauser et al (2011), Grattan (2014) 
Quiggin (2014, p. 20) states that, '...in the absence of sophisticated metering, electricity is a fairly simple commodity. Many households would have preferred to continue buying their electricity from the distributor [as opposed to a competitive retailer]'. Such a statement could be reworded to make the point that implementation of a contestable metering and retail framework should have been a priority of policy makers at the commencement of the NEM. It is indeed puzzling why 16 years after the introduction of competition, energy metrology (metering) in Australia is only now being deregulated despite the rapid technological development of smart-enabled remotely read technologies in the 2000s. The decline in load factors driven by demand growth divergence may indeed have been partially averted by early adoption of Time-of-Use (ToU) or capacity pricing utilising digital metering. Simshauser and Downer (2012) outline the significant improvements in capacity utilisation that can be achieved through more dynamic pricing structures. They have found that relatively simple ToU pricing such as a peak, off-peak and shoulder pricing framework could yield a capacity utilisation and pricing improvement of nine percentage points, achieved through consumers shifting consumption within periods and reducing future growth in peak demand.

Shortly after the commencement of the microeconomic reform of the electricity industry, Abbott (2002) measured and forecast the significant productivity improvements that could be achieved as a result of the Australian energy markets reform process. However, he could never have predicted the stalling of product market reform (electricity retail pricing structures). Product market reform has not yet been completed despite wholesale or input market reform having been implemented nearly twenty years ago. Energy prices remain regulated in two jurisdictions (Queensland electricity and NSW gas) and the lack of metering contestability has prevented innovation around tariff design - a pre-requisite for stimulating demand in off-peak consumption periods and reducing demand at times of peak consumption.

It is important to note that these issues are not unique to Australia. Policy makers around the world have baulked at implementing difficult product market reforms associated with energy 
markets. Joskow (2006, p. 1), in considering electricity market reform in the US stated, 'The framework for supporting retail competition has been less successful, especially for small customers.' Many market structures have failed to embrace new metering technologies through contestable metering frameworks (see Nelson and Simshauser, 2014) and implement serious tariff reforms that would prevent the manifestation of death spiral conditions. It is arguable that the microeconomic reform process also failed to account for the (then) emerging issue of anthropogenic climate change in the 1990s. Pollitt and Haney (2013, p. 9) observe that when markets were liberalised, 'competitiveness was the overriding priority. Today, competitiveness, energy security and decarbonisation are the three main energy policy priorities'.

So why is all this important in the context of facilitating demand response within Australia's NEM at the wholesale or retail level? Simshauser (2014), Quiggin (2014) and Simshauser and Nelson (2014) all observe that pricing structures based upon simple accumulation metering and 'average cost' pricing have led to a decline in electricity sector productivity. The brief history of the market documented in this article supports this thematic. Metering services for all customers (including households) are currently being deregulated and more cost reflective network tariffs have been mandated by the AEMC (AEMC, 2012). The alternative policy proposal from the 'Power of Choice' report focuses solely on the wholesale market which, we may note at this stage of our argument, has not materially contributed to higher costs for consumers. It is questionable therefore, whether policy makers with scarce resources should be devoting time and effort to facilitating greater wholesale market demand response when such a reform is not focused on the component of the supply chain that has led to greater end user pricing pressures. 


\section{Overview of demand response literature}

In 2012, the AEMC released its 'Power of Choice' report which contained several

recommendations in relation to increasing consumer participation within energy and gas markets.

As noted earlier, this article focuses on assessing the economics of two of the most prominent of these recommendations. Firstly, the introduction of a demand response mechanism (DRM) that would facilitate demand-side participation in the wholesale electricity market; and secondly, the deregulation of metering services to establish contestability for electricity metering and the introduction of cost-reflective network and retail pricing (see AEMC, 2012).

There is no shortage of literature on engaging consumers and demand-side response in electricity markets. Broadly, the literature can be separated into two types as identified by Masiello et al. (2013, p. 9): the utilisation of differentiated retail pricing to provide customers with opportunities for reducing or increasing consumption on the basis of pricing differentiated by capacity or time (as opposed to energy throughput); and introduction of demand-side response mechanisms in wholesale market design. The observation by Masiello et al. is important as the distinction used can be applied to the two primary processes being pursued through the AEMC Power of Choice report: cost-reflective retail/network pricing (which has been already been examined quantitatively by Australian researchers); and the introduction of a wholesale market DRM (which has been largely unexplored quantitatively in the Australian literature).

Borlick (2011) and Bushnell and Wolak (2011) highlight many of the problems associated with a demand response mechanism. Borlick's analysis demonstrates that payments for demand response will exceed benefits unless a complicated settlement mechanism is utilised. In the particular case of the type of demand response mechanism being proposed in Australia, analysis by Borlick (2011, p. 8) implies, '[DRM] overcompensates demand response, thereby reducing market efficiency and unfairly burdening small electricity consumers'. Van Horn and Gross 
(2013, p. 86) state that 'it is highly questionable whether all the reported economic and emission benefits...can actually be realised'.

On the other hand, implementation of differential capacity or time-based pricing structures has produced measurable reductions in peak demand. Faruqui and Sergici (2013, p. 55) conclude, 'customers do indeed respond to rising prices by lowering their peak demand in a consistent fashion. This supports the case for rollout of dynamic pricing wherever advanced metering infrastructure is in place'. As noted earlier, Simshauser and Downer (2012) modelled relatively simple ToU pricing structures and found improvements in capacity utilisation of nine percentage points are possible. This is consistent with international studies. Figure 3 shows the results of 163 US tariff trials with reductions in peak load of between $10 \%$ and $60 \%$ achievable through the adoption of time/capacity differentiated tariffs. Simshauser (2014) has also demonstrated the significant efficiency gains that could be achieved through the use of more cost-reflective tariff designs. 
Figure 3: Peak load reductions from 163 tariff pilots

Peak Load Reduction

$(\%)$

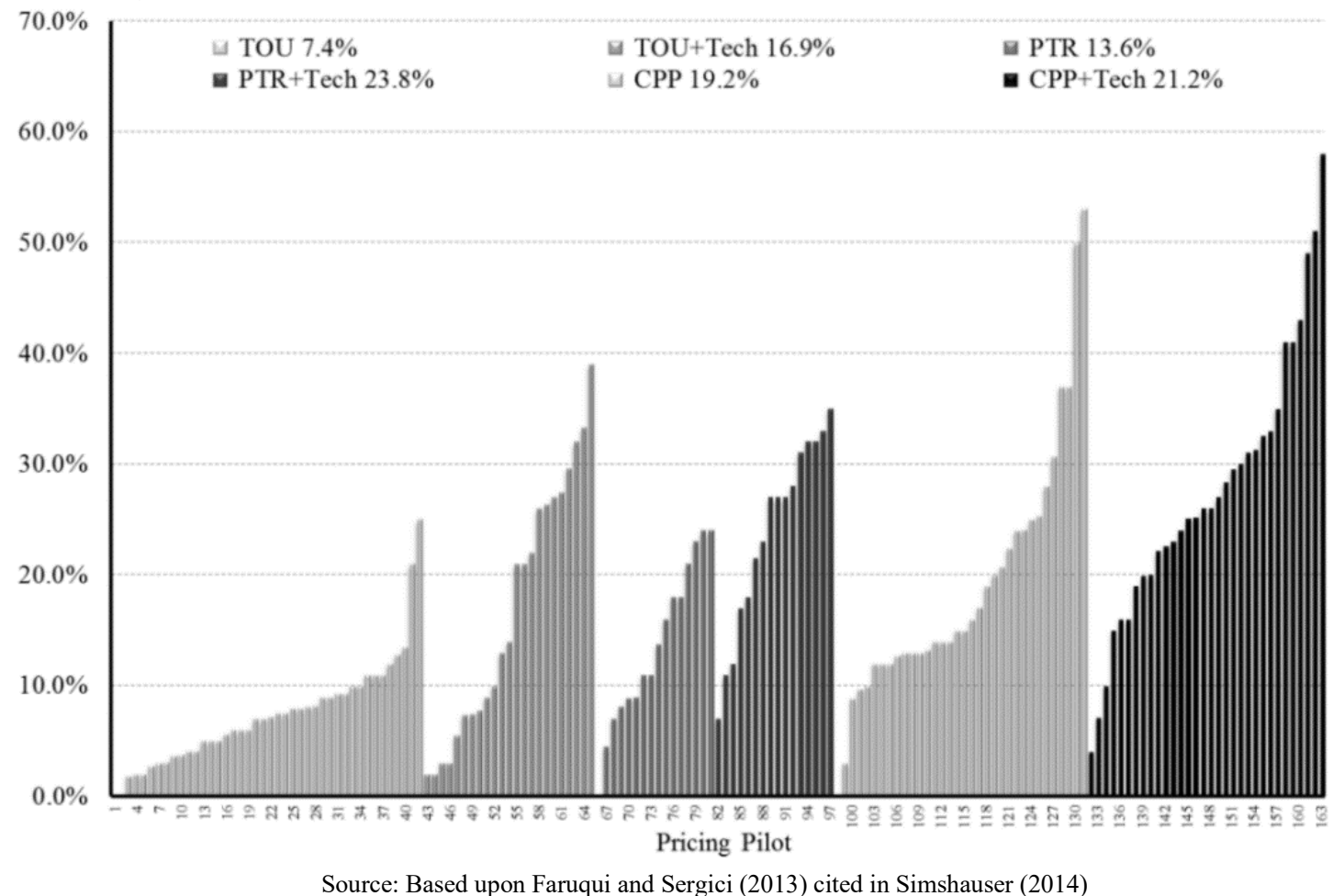

\section{Assessing the effectiveness of wholesale and retail level demand response}

In assessing the effectiveness of demand response generally, we may note the criticisms of many market participants and stakeholders through public submissions made to the Australian Energy Market Operator (AEMO) in the specific context of its development of a DRM proposal: no clear public policy objective or market failure has been articulated. AEMO states on its website that, 'DRM is one of the ways to manage energy price rises driven by the network investment required to meet peak demand ${ }^{\prime}$. Accordingly, we have established a simple assessment criteria for the two possible policy approaches identified by Masiello et al. (2013) and currently being assessed within Australia through the policy processes outlined in Section 3. The criteria is: how effective will the policies be in efficiently reducing growth in system capital augmentation by avoiding increases in peak demand, while at the same time encouraging better utilisation of existing infrastructure through improved tariff cost-reflectivity/exposure to the wholesale pool price?

\footnotetext{
${ }^{6}$ Available at: http://www.aemo.com.au/Electricity/Market-Operations/Demand-Response-Mechanism, accessed online on 14 November 2014.
} 


\subsection{Demand response aimed at avoiding wholesale energy market costs}

The DRM concept developed by AEMO is relatively simple and useful for assessing the economic benefits of direct wholesale market demand side participation. Electricity users contract with a 'demand-side aggregator' which pays the user to reduce demand when electricity prices exceed a particular threshold. This aggregated demand reduction is then bid into the NEM and dispatched if it is economic relative to other bids of supply-side generators and demand-side aggregators in each half-hourly settlement interval (aggregated across 5 minute sub-intervals). However, the proposed settlement process is anything but simple. The market operator (AEMO) would be required to calculate a 'baseline' of energy consumption that would have occurred if the aggregated demand reduction had not been adopted. The difference between the baseline and actual consumption would then be remunerated at the clearing NEM spot price. Retailers would be billed by AEMO for electricity purchases based upon the baseline, rather than actual consumption. The process is likely to lead to inherent cross-subsidies between different participants. AEMO (2013) provides a detailed explanation of the nature of the proposal and its associated settlement procedures which we consider to be complicated.

The DRM proposal under investigation is to be available initially to customers with 'large' consumption $^{7}$ and a digital smart meter that records consumption in half-hour increments (known in the electricity industry as a Type 1 to 4 metering installation). In practice, this means that those customers who would be eligible to participate in the DRM are already able to be exposed to realtime wholesale market pricing. On the other hand, residential and small business customers, utilising primarily quarterly read accumulation meters (known as Type 6 within the industry), generally pay 'average cost' end-use tariffs. It is worth noting that Australia's largest 250 business users consume 40 percent of national electricity output (Simshauser and Nelson, 2013, p. 67). Nelson and Orton (2013, p. 4) calculated that the utilisation rate of residential consumers is

\footnotetext{
${ }^{7}$ Large consumption is above 100-160 MWh depending upon the State definition. For contrast, average household electricity consumption is around 6.5 MWh. 
around $40 \%$ whereas the same rate for the entire sector is between 60 and $70 \%$. The flatter load profile of large industrial customers indicates, ceteris paribus, that they are less likely to have opportunities for 'load shifting' whereby peak demand is shifted into off-peak periods.

An argument for a DRM is that barriers exist for end users of electricity to adjust their consumption in response to wholesale electricity market spot pricing signals ${ }^{8}$. However, only a handful of electricity consumers directly participate in the wholesale generation market. Most energy consumers purchase electricity from retailers who participate on their behalf and on-sell energy using simplified tariff structures (including flat tariffs) which provide certainty and stability through expert management of wholesale market exposure risk. However, these stable flat tariffs tend to dampen incentives to limit consumption during periods of peak demand or high spot prices, and over time can lead to inefficient consumption patterns, and in turn, inefficient investment in new generation capacity. A critical policy question is whether a DRM would overcome these barriers by providing a mechanism for consumers to bid in their demand reduction to the market when the opportunity cost of not using energy is lower than the electricity pool price. The benefits are most pronounced in markets where supply and demand are closely matched at the wholesale level and shifting demand from peak periods will avoid energy shortages (unserved demand) or delay immediate investment in generation and transmission capacity that is likely to be underutilised.

\footnotetext{
${ }^{8}$ Submissions by industry participants, articulating arguments both for and against DRM, can be found here: http://www.scer.gov.au/workstreams/energy-market-reform/demand-side-participation/wholesale-market-demand-responsemechanism-in-the-national-electricity-market/ 
Theoretically, a DRM proposal or the introduction of time or capacity differentiated end-user pricing should provide consumers with similar opportunities to optimise consumption to minimise their wholesale energy market costs ${ }^{9}$. Where the value of lost production or utility is exceeded by reduced electricity costs, customers would logically seek to curtail their own consumption according to their utility function. As noted previously, the customers to be initially included as potential providers of demand response through the DRM are already likely to be able to take advantage of time or capacity based end-user pricing. Energex (2014a, p. 10), the southeast Queensland distribution network provider, is a useful example of the significant tariff diversity currently in place for customers with advanced digital smart metering (Type 1 to 4). This is an important observation as policy makers must ask why the introduction of a DRM is necessary given economic signals already exist for customers to reduce peak wholesale market electricity consumption.

Table 3: AEMO estimates of existing Demand-Side Participation: DSP (MW)

\begin{tabular}{cccccc}
\hline Price Threshold & QLD & NSW & VIC & SA & TAS \\
\hline Prices $>$ \$300/MWh & 49 & 18 & 65 & 39 & 0 \\
Prices $>$ \$500/MWh & 49 & 22 & 77 & 41 & 5 \\
Prices $>$ \$1000/MWh & 51 & 24 & 83 & 43 & 5 \\
Prices $>$ \$7500/MWh & 61 & 85 & 214 & 126 & 37 \\
Prices $=$ MPC & 123 & 219 & 336 & 147 & 56 \\
\hline
\end{tabular}

Source: AEMO (2014)

In practice, a significant volume of demand-response is already occurring in the NEM at the wholesale market level. AEMO estimates that there is approximately $800 \mathrm{MW}$ of demand-side participation (DSP) available at varying price thresholds (AEMO, 2014) ${ }^{10}$. This is shown in Table 3. Various retailers offer 'interruptible contract' services to customers where the value of reduced electricity costs at times of peak electricity demand exceed costs associated with reducing their consumption. ${ }^{11}$ Some market participants may argue that greater volumes of demand response

\footnotetext{
9 The AEMC consider that the most economically efficient outcome for the market is when consumers face the true cost of supply. In the absence of fully cost-reflective pricing, the DRM creates a similar set of incentives and behaviors with respect to efficient consumption during wholesale electricity market peak and non-peak times (AEMC, 2012).

${ }^{10}$ The AEMC is also proposing to increase the effectiveness of AEMO estimation of DSP within the NEM - see http://www.aemc.gov.au/News-Center/What-s-New/Announcements/Draft-rule-to-better-inform-AEMO-of-demand-side-pa, Accessed online on 18 December 2014.

${ }^{11}$ Further information on the types of DSP are available at: http://www.aemo.com.au/Electricity/Planning/Forecasting/NationalElectricity-Forecasting-
} 
should be being incentivised and facilitated at times of peak demand given the market price cap (MCP) is around $25,000 \%$ higher than underlying average wholesale prices. However, economic incentives for demand response in recent years have fallen significantly due to material reductions in electricity demand and the installation of significant additional capacity. Figure 4 shows the significant 'grinding down' of electricity demand projections since 2009. Also shown is the material contraction in actual demand - a reduction of around $8 \%$ since it peaked at the end of last decade.

Demand contractions have resulted in significant oversupply of generation capacity and subsequently to the benign electricity pricing of the past few years in the NEM. This is shown in Figure 5 where average annual prices are contrasted with inflation. Average prices in the NEM are no higher in real terms than they were at the commencement of the microeconomic reform process in the late 1990s. In fact, it could be argued that the current conditions in the NEM are very similar to those that were present at the time of market start - notable oversupply of generation capacity.

Report/ /media/Files/Electricity/Planning/Reports/NEFR/2015/2015\%20Demand\%20side\%20participation.ashx, Accessed online on 9 August 2015. 


\section{Figure 4: Annual demand projections and actual growth}

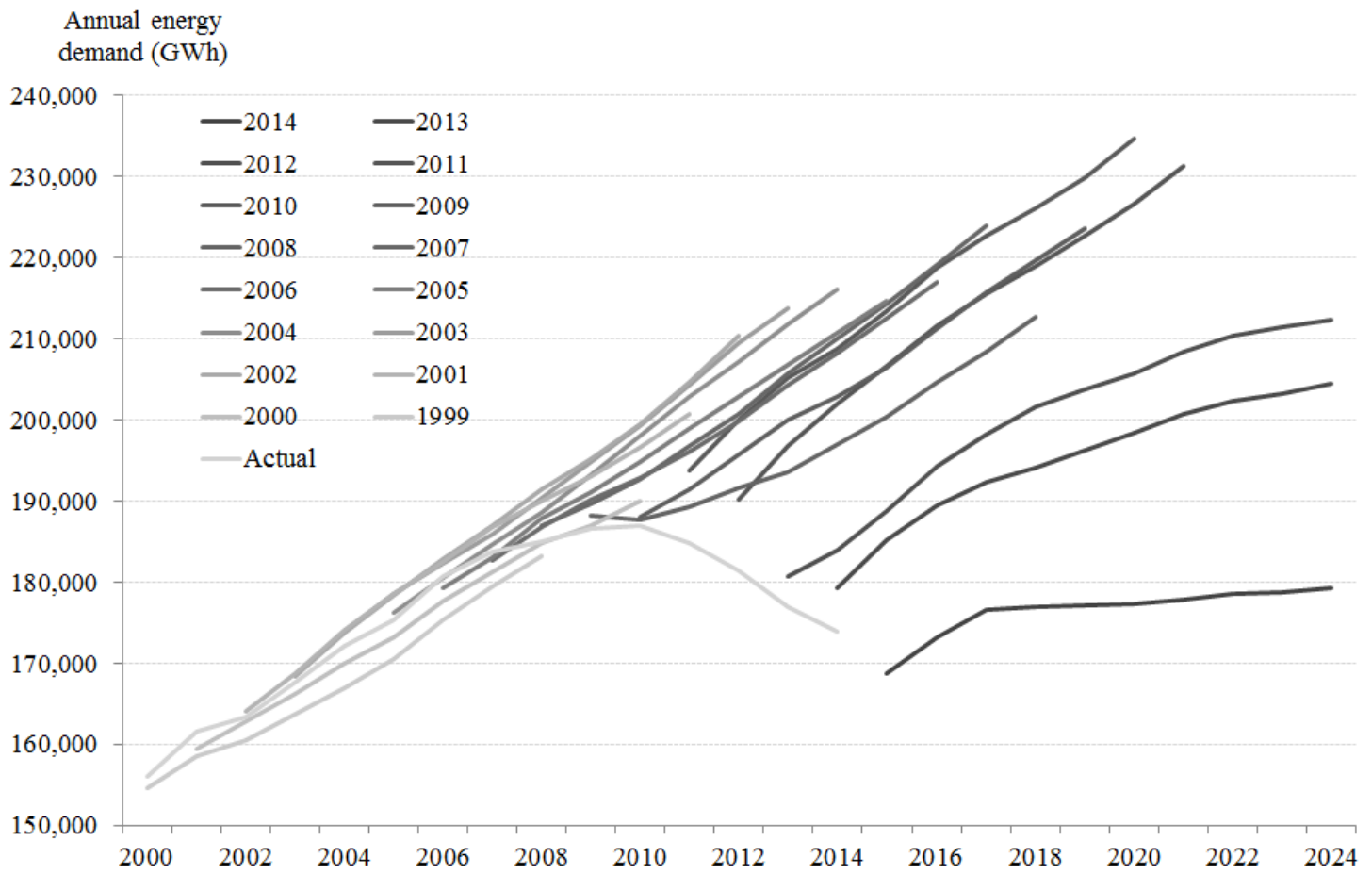

Source: Frontier Economics analysis of AEMO data (Sioshansi, 2015)

Figure 5: NEM pricing (1998 to 2014)

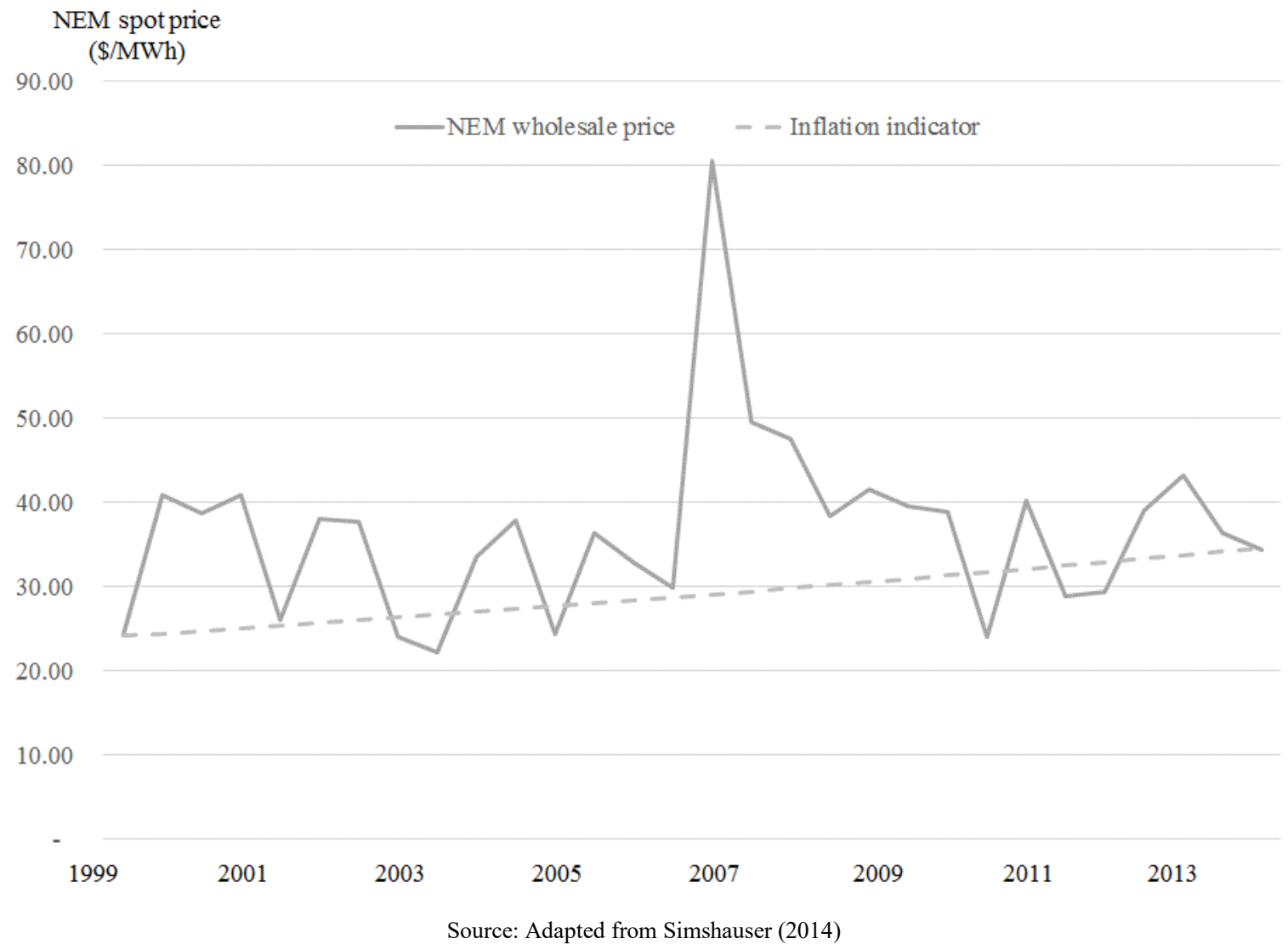


The current oversupply in the NEM, based upon FY14 load data, is documented in Table 4 and exceeds 7,100 MW - the equivalent of three large baseload coal-fired power stations.

Table 4: Optimal plant mix

\begin{tabular}{ccccc}
\hline Plant Type & Optimal Mix & Actual Mix (FY14) & Imbalance & Weighting \\
\hline Baseload & 19,800 & 25,100 & 5,300 & overweight \\
Intermediate & 3,700 & 5,700 & 2,000 & overweight \\
Peaking & 14,200 & 13,700 & -500 & underweight \\
Renewable & 2,800 & 3,000 & 200 & overweight \\
\hline Total & 40,500 & 47,600 & 7,100 & oversupply \\
\hline \multicolumn{4}{c}{ Source: Nelson, Reid and McNeill (2014) }
\end{tabular}

However, the utilisation of wholesale market demand response through a DRM is also a function of pricing volatility. Appendix 1 shows half-hourly pricing for South Australia, New South Wales, Queensland and Victoria since 1999. The trend towards less volatility in each jurisdiction, particularly from 2010, is observable. High pricing events for the first half of the series (i.e. between 1999 and 2006) for the four jurisdictions number 1,591. For the second half of the series (i.e. between 2007 and 2014), the number of high pricing events is 1,153. Overall, high pricing events have declined by $28 \%$, with much of the reduction observable over the past few years. With such significant reduction in market volatility, as expected there is reduced appetite for demand response services given the relatively limited economic opportunities when compared with the transaction costs of establishing capabilities to reduce electricity demand.

In other words, there is no market failure occurring at the wholesale market level - it is simply less economic for consumers to explore demand-side opportunities at present given benign pricing and volatility. Such a conclusion is further supported by consideration of the market for cap contracts. Such contracts allow the purchaser to 'call' on generation when a strike price exceeds a certain threshold - often $\$ 300 / \mathrm{MWh}$. Historically, such contracts have been used as insurance for events where prices reach very high levels. The significant oversupply of generation and depressed demand outlook has resulted in a decline in cap contract prices. Figure 6 shows a weighted average of cap contract pricing in each of the major jurisdictions. In each state, there 
has been a steady decline in pricing but importantly not turnover (see Appendix 2). In fact, prices at current levels are significantly lower than the 'capital cost' of building a new open-cycle gas turbine (OCGT) which would provide a physical (as opposed to financial) hedge against extreme pricing events ${ }^{12}$. In other words, there is consensus within the market and industry that there is little requirement for new OCGT capability to mitigate against future pricing events.

\section{Figure 6: Weighted average of Cap contract pricing}

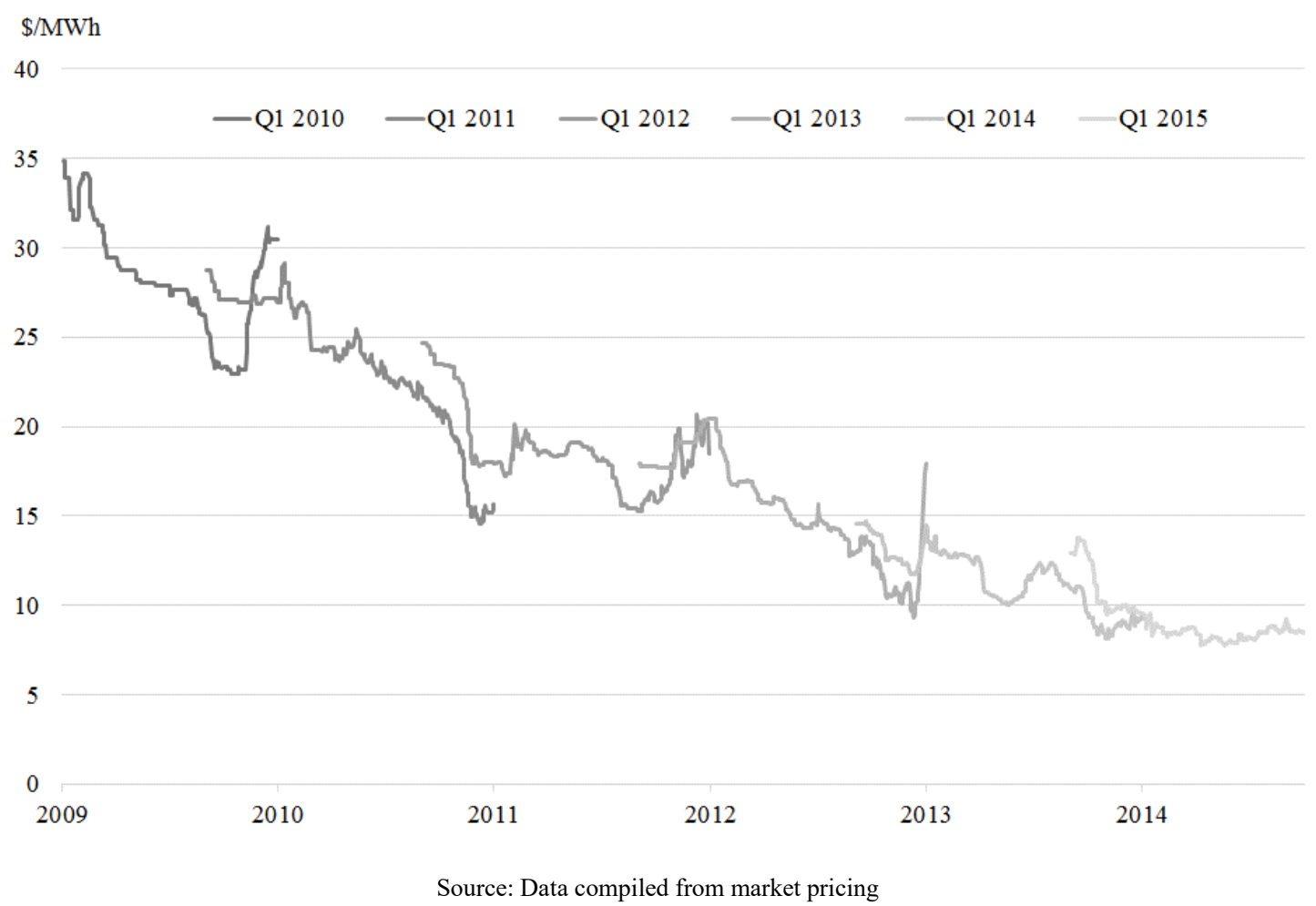

A critical question for policy makers is whether the current structural oversupply of the NEM will persist into the future or whether demand growth will absorb the capacity with the reintroduction of greater levels of demand volatility, thereby increasing the attractiveness of demand-side participation in the NEM. AEMO (2014) has estimated that even under the strongest demand growth scenario, there is still likely to be around 5,000 MW of surplus capacity on the Australian east-coast in 2023/24. Figure 7 shows the range of potential outcomes forecast by AEMO in its Statement of Opportunities, the annual system forecast of demand and supply. Within ten years, it

12 Nelson et al. (2013) provide estimates of the 'capital costs' of new OCGT generation - approximately \$15/MWh. 
is possible that oversupply of generation capacity could be as high as $12,000 \mathrm{MW}$. Clearly, in either of these scenarios, wholesale market demand-side participation through a DRM is unlikely to be very successful given the oversupply. To demonstrate this concept further, Figure 8 shows the AEMO forecast of half-hourly demand in the South Australian market to 2040. The trend indicates peak demand in 2040 is no higher than it is today.

Figure 7: Estimated surplus capacity in NEM
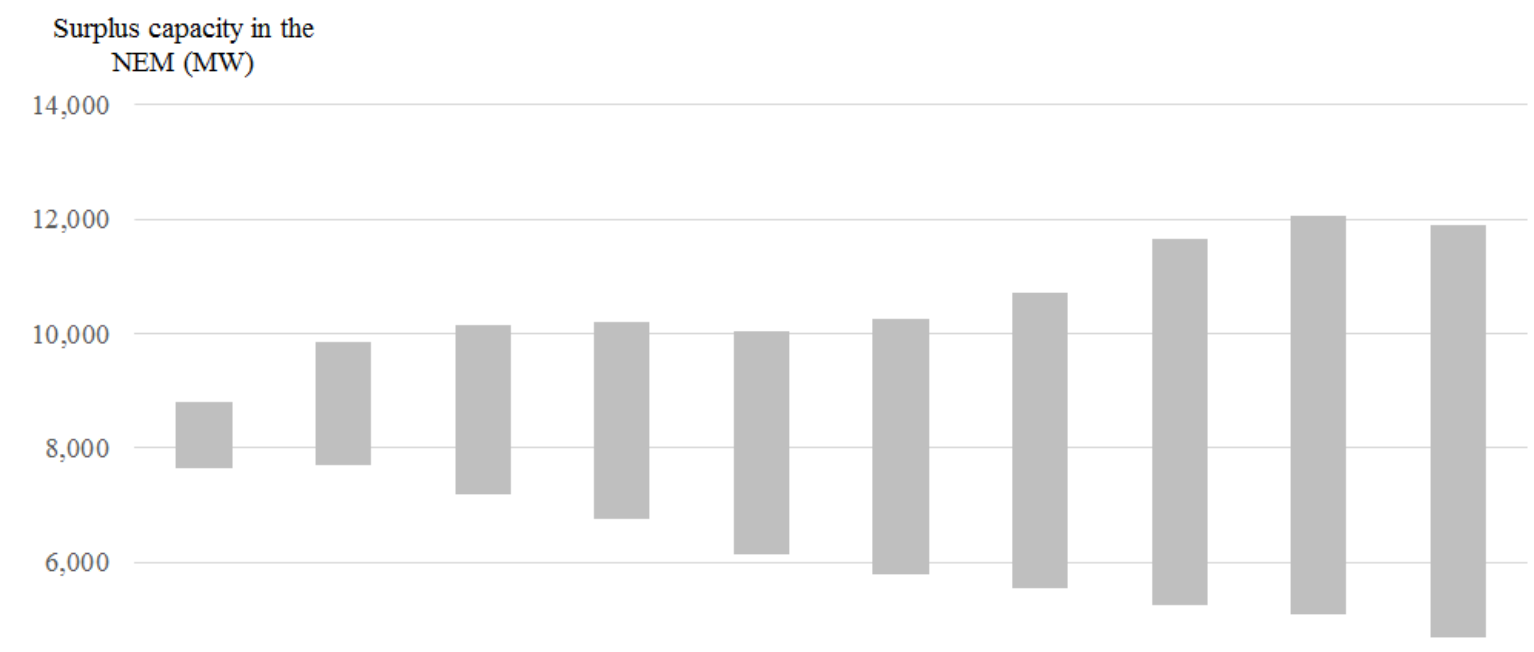

4,000

2,000

0

$2014-15 \quad 2015-16 \quad 2016-17 \quad 2017-18 \quad 2018-19 \quad 2019-20 \quad 2020-21 \quad 2021-22 \quad 2022-23 \quad 2023-24$
Source: AEMO (2014)


Figure 8: AEMO SA half-hourly demand forecast

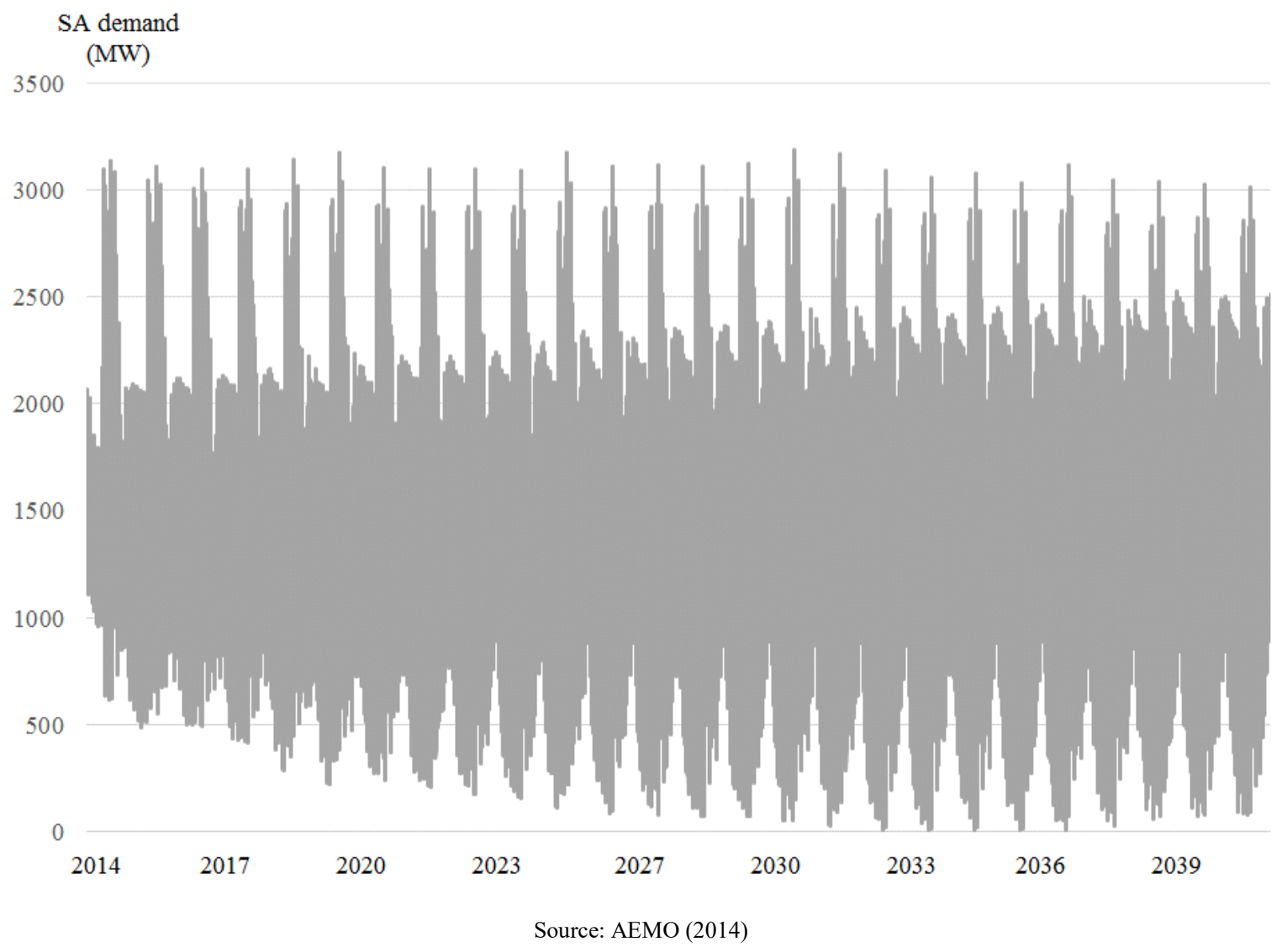

In summary, a DRM is likely to be unnecessary given customers are already exposed to real-time wholesale market pricing fluctuations through time or capacity differentiated pricing. At a more practical level, the outlook for wholesale market demand-side participation is depressed given weak pricing conditions and associated declining volatility. One of the main arguments for a DRM involves network and retail businesses being unwilling to offer cost-reflective tariffs, necessitating wholesale market demand response bidding (Memery and Kuiper, 2014). Importantly, such concerns would be addressed by introducing cost-reflective retail and network pricing - the alternative presented in this article. In our view, policy makers are better placed focusing on end-user metering and pricing contestability as such policy reforms allow customers to reduce electricity costs by shifting consumption to lower than average pricing periods. This allows greater utilisation of existing generation and network infrastructure and a reduction in system average costs. Furthermore, such dynamic end-user pricing also allows for pricing signals 
to be used to incentivise consumption at times of low-emission energy production. As an example, such pricing structures could be used to increase consumption overnight when wind farm energy output is at its highest. By reforming pricing in this way, energy policy could also facilitate environmental externality policy objectives in the form of reduced greenhouse emissions more thoroughly.

\subsection{Demand response aimed at avoiding network and retail costs}

The adoption of a contestable metering framework with a greater emphasis on cost-reflective network and retail pricing would allow for the transmission of pricing signals that would reflect both system wide infrastructure and localised network congestion issues. Simshauser and Downer (2012) and Simshauser (2014) demonstrate the substantial economic gains that could be achieved with the adoption of such pricing structures - a nine percentage point improvement in the rate of capacity utilisation and associated pricing benefits. In fact, Simshauser and Downer (2012) forecast gains of $\$ 1.6$ billion per annum across the NEM if dynamic pricing structures were adopted. ${ }^{13}$

Alternatively, while the DRM proposal identified in this article is to be initially focused on large industrial customers, it is possible that it could be expanded to allow all customers to participate through bids of aggregated demand reductions. Recall from Section 2 that the major driver of higher costs to electricity consumers is the significant expansion of network infrastructure, reflected in higher network tariffs. Accordingly, it is necessary to consider whether a DRM focused on wholesale pricing would be as effective as the use of end-user metering and pricing contestability in avoiding future network capital augmentation associated with peak demand growth.

\footnotetext{
13 The $\$ 1.6$ billion estimated by Simshauser and Downer's study is comprised of reductions in electricity usage charges achieved through both reductions in consumption and shifts of usage from peak to off-peak periods. 
Figures 8 through 11 show the correlation between net system load profile demand (used as a proxy for Type 6 metered residential electricity demand) and wholesale market pricing outcomes in each NEM jurisdiction. A cursory glance at these charts demonstrates there is a very low correlation between wholesale electricity market pricing and demand within residential networks. The line of best fit in each jurisdiction has a statistical $\mathrm{R}^{2}$ of between just 0.01 and 0.38 . This is an important observation as network capital expenditure is driven by individual network peak demand, not necessarily the aggregate State peak demand. Such low correlation between net system load profile demand and wholesale market pricing indicates that a DRM proposal would be likely to be ineffective at preventing growth in peak network demand at the element (i.e. substation) level.

Energex (2014b, p.7) supports this analysis: '..defining a peak period during which to register and measure peak demand is difficult as localised network peaks occur at different times across the network. Most residential peaks occur across the network between 4 and 8pm, but peaks do occur across the network at many different times.' In other words, a DRM proposal focused on wholesale pricing signals will not be effective in pricing localised peak demand network constraints which are an underlying driver of higher network capital expenditure - which Section 2 highlighted has been one of the major drivers of higher end prices for consumers. A DRM would only be effective if localised network peak demand perfectly correlated with system-wide peaks. Our analysis shows that higher wholesale prices do not occur at times of peak household electricity demand (represented by the Net System Load Profile) and therefore would not be useful for incentivising households to reduce peak electricity demand. The evidence presented in this paper, and by east-coast network businesses (see Energex, 2014b as an example), indicates that wholesale electricity pricing would be relatively ineffective at reducing local network peak demand growth as there is a mismatch between wholesale pricing and household peak demand. 
Figure 9: Correlation between household consumption and NEM wholesale pricing (SA)

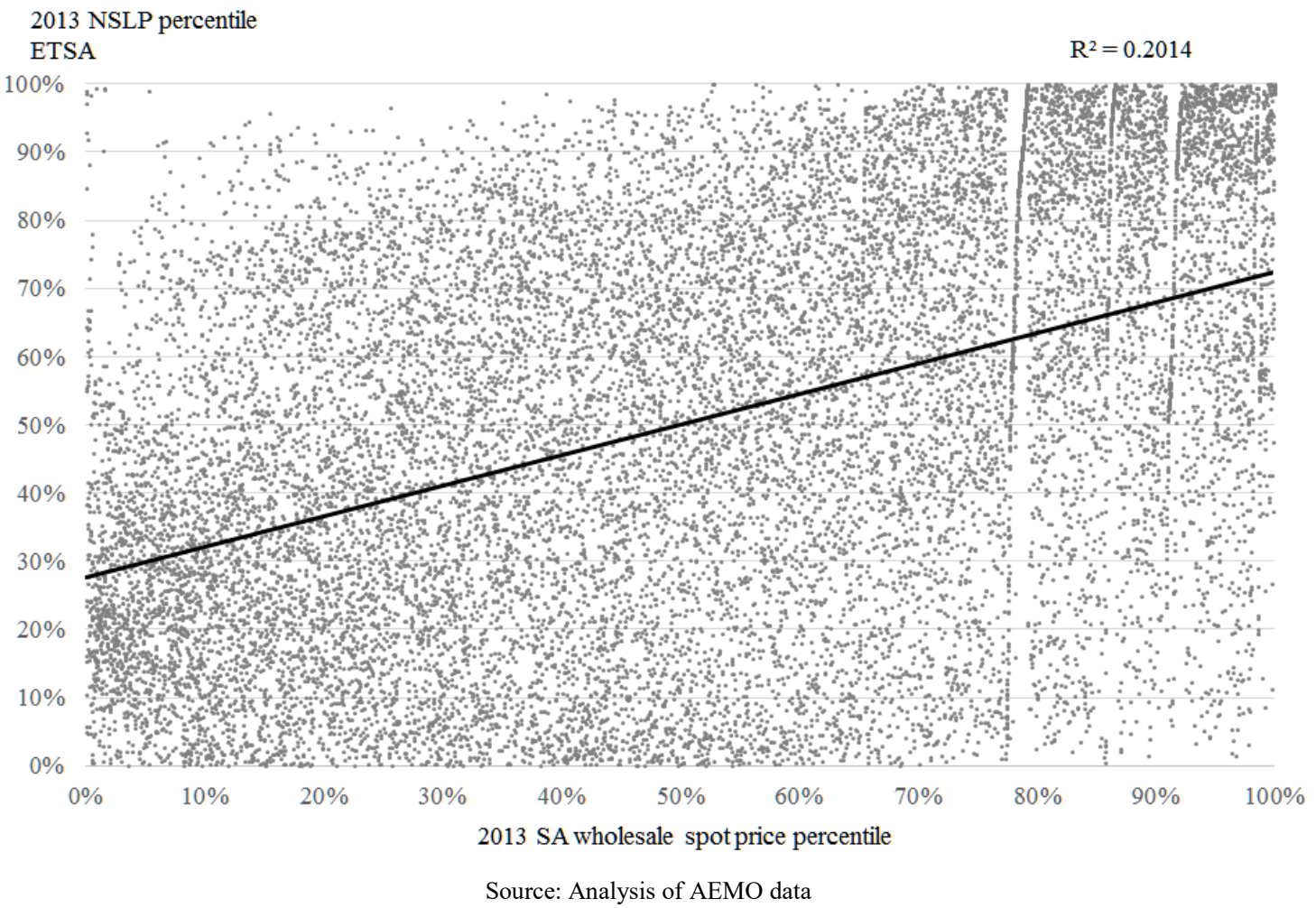

Figure 10: Correlation between household consumption and NEM wholesale pricing (VIC)

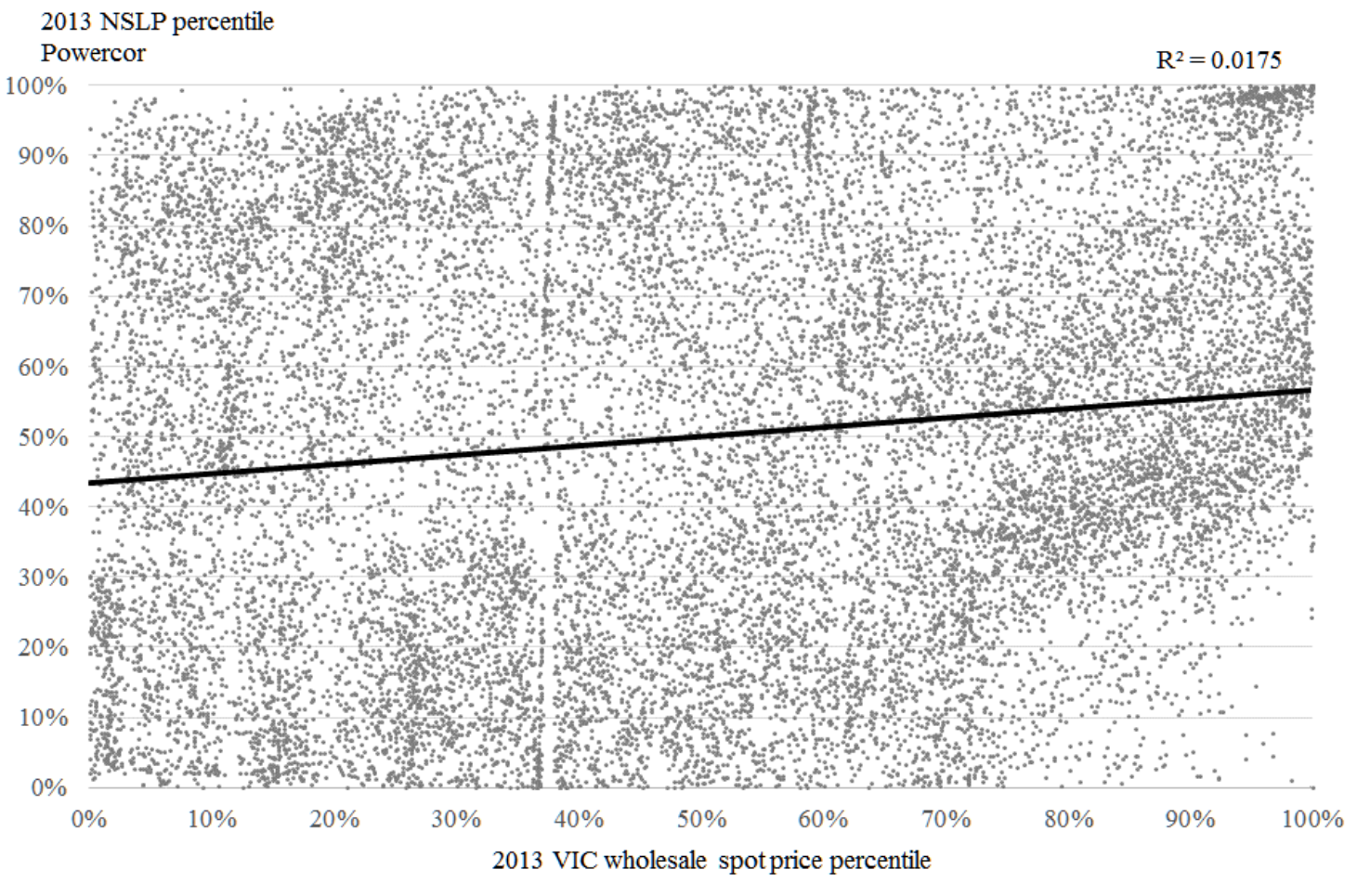

Source: Analysis of AEMO data 
Figure 11: Correlation between household consumption and NEM wholesale pricing (NSW)

2013 NSLP percentile

Energy Australia

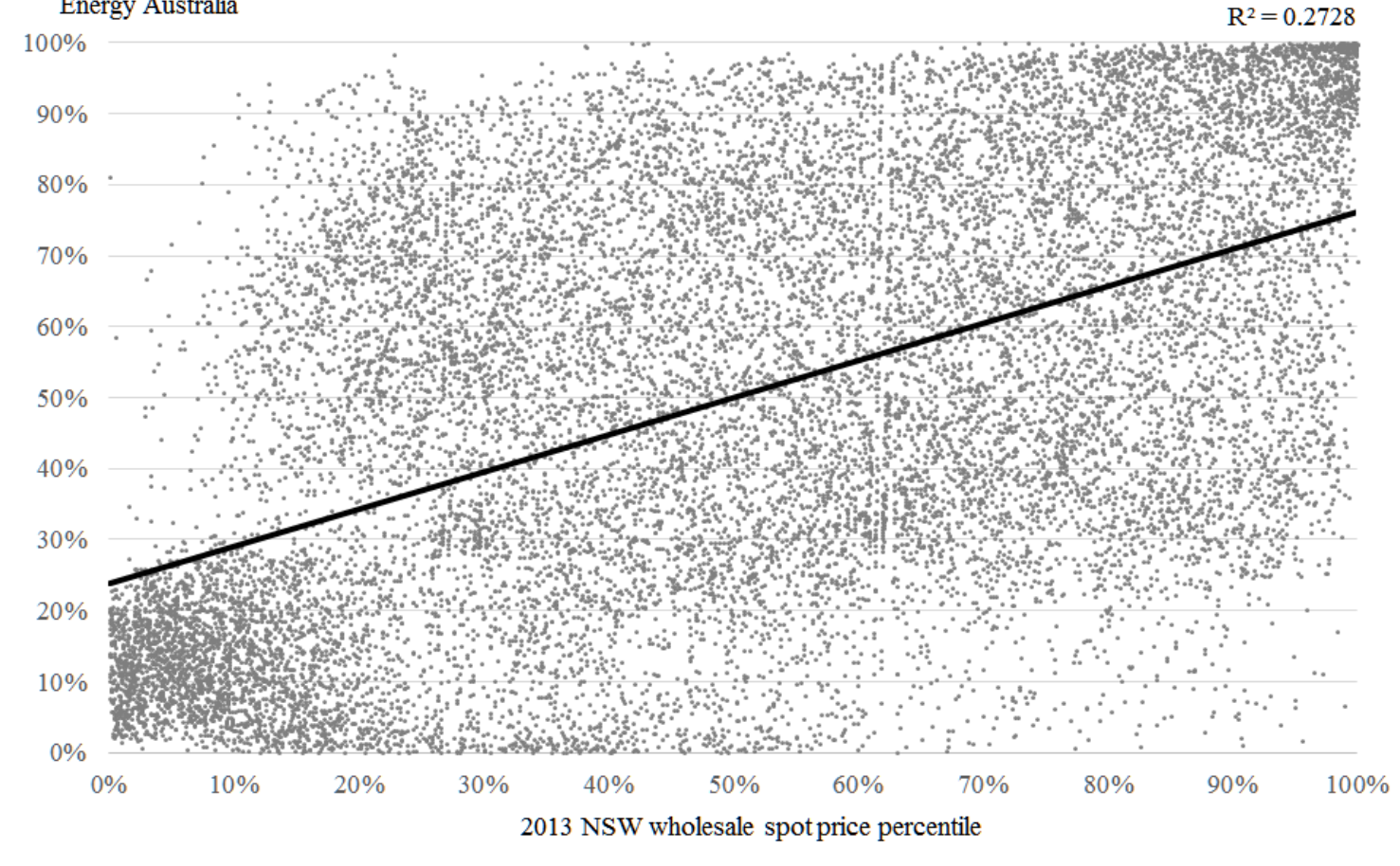

Source: Analysis of AEMO data

Figure 12: Correlation between household consumption and NEM wholesale pricing (QLD)

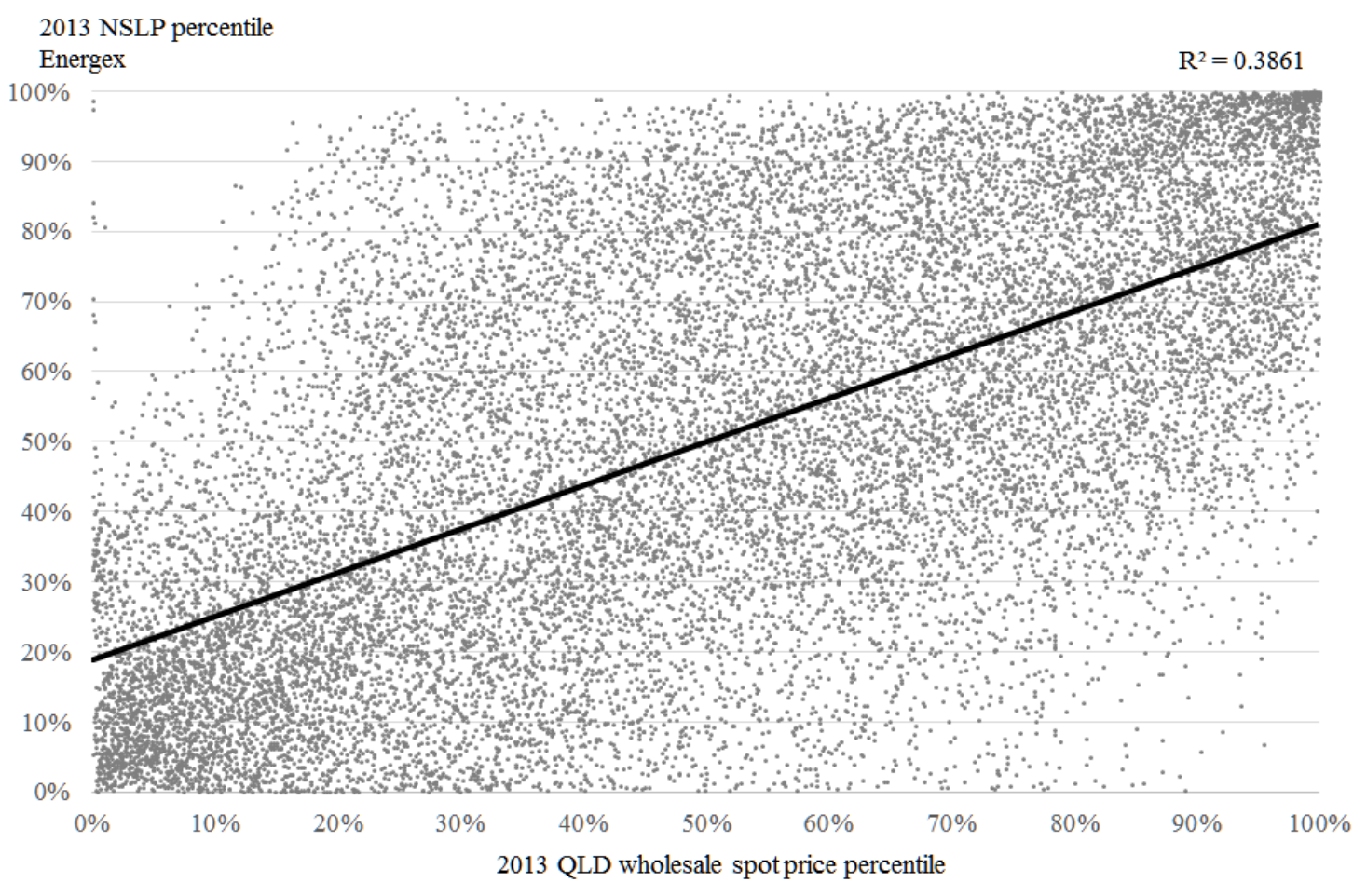

Source: Analysis of AEMO data 


\subsection{Summary of analysis}

Section 2 established that there has been a market failure in relation to electricity pricing. Prices at the retail level do not reflect the cost of supply and this has led to sub-optimal consumption.

However, our analysis shows that wholesale markets are operating efficiently with current depressed wholesale spot and Cap contract prices reflecting significant oversupply and a depressed demand outlook. On the other hand, network and retail pricing is currently not costreflective and has resulted in significant worsening of capacity utilisation and higher average costs. Table 5 presents a summary of the effectiveness of a DRM when compared with metering contestability and time or capacity differentiated pricing structures, as per the taxonomy identified by Masiello et al. (2013).

Table 5: Summary of effectiveness of policy options

\begin{tabular}{|c|c|c|c|}
\hline $\begin{array}{l}\text { Market } \\
\text { Segment }\end{array}$ & $\begin{array}{c}\text { DRM } \\
\text { Effective }\end{array}$ & $\begin{array}{c}\text { Dynamic } \\
\text { Retail } \\
\text { Pricing } \\
\text { Effective }\end{array}$ & Reasons \\
\hline Wholesale & No & Yes & $\begin{array}{l}\text { Generation market significantly oversupplied with no } \\
\text { requirement to avoid new capacity augmentation for the } \\
\text { foreseeable future. Customers with flexible business loads } \\
\text { already on digital meters, enabling real-time demand response } \\
\text { to higher prices. Dynamic pricing allows for 'load shifting' } \\
\text { rather than simple 'load reductions' thereby improving } \\
\text { capacity utilisation. }\end{array}$ \\
\hline $\begin{array}{l}\text { Networks } \\
\text { and Retail }\end{array}$ & No & Yes & $\begin{array}{l}\text { Value of DRM to customer based upon wholesale pricing } \\
\text { signals, not the value of avoided network capacity costs or } \\
\text { network augmentation. Little correlation between wholesale } \\
\text { pricing signal and local network constraint. Metering } \\
\text { contestability and cost-reflective network tariffs would allow } \\
\text { more appropriate pricing signals to be adopted which reflect } \\
\text { drivers of cost across the entire supply chain. }\end{array}$ \\
\hline
\end{tabular}

\section{Concluding Remarks}

This article has argued that failure to complete product market reform within the Australian electricity industry has led to significant reductions in capacity utilisation, increases in unit costs and higher electricity prices. The lack of end-user cost reflective pricing and metering contestability led to overconsumption of peak electricity and underconsumption of off-peak electricity particularly in the residential and small business segment. As a result of the deterioration of electricity pricing competitiveness and consistent with the taxonomy identified in 
Masiello et al. (2013), policy makers in Australia are currently focused on improving demandside participation in electricity markets. Specifically, they are considering the introduction of a DRM to provide incentives based on wholesale prices and introducing requirements for costreflective network/retail pricing.

Our analysis suggests that a DRM is likely to be relatively ineffective for several reasons: the economic incentives for demand-side participation to reduce wholesale electricity costs already exist for customers with digital metering; there is little correlation between network congestion created by household consumption and wholesale market pricing; and other studies (such as Simshauser and Downer, 2012 and Simshauser, 2014) show that the use of time or capacity differentiated end-user pricing is a superior policy instrument as it provides incentives for load shifting rather than load reductions per se, thereby increasing opportunities for improved capacity utilisation and lower average unit system costs.

Our conclusion is supported by assessments made in other economic studies. In analysis completed for the COAG Energy Council, Oakley Greenwood (2014) found that the introduction of a DRM in the NEM would reduce electricity generation costs by just $\$ 2.6$ million (NPV) over the two decade modelling period from 2017 with much of the benefit occurring well into the future. Estimates by industry participants indicate that the capital costs of introducing systems and processes to facilitate a DRM could be as high as $\$ 120$ million. Given the proposal involves immediate significant cost and possible benefits in the future, it would be wise to pause until it is clear that wholesale market conditions move in the direction that would warrant the policy's introduction. In contrast, Simshauser and Downer (2012) found that the benefits of introducing differentiated retail pricing could be as high as $\$ 1.6$ billion per annum. This is in addition to the $\$ 120$ million reduction in deadweight losses that could be achieved through the introduction of contestable metering services (see Nelson and Simshauser, 2014). While there will be costs incurred through the adoption of smart metering technologies, the market-led adoption model 
being utilised will ensure that customers only incur such costs where there is a clear customer value proposition. In other words, such costs will need to be outweighed by benefits (achieved through load-shifting and peak demand reductions). Our advice to policy makers is clear: expedite the introduction of contestable metering and facilitation of cost-reflective network and retail pricing; and defer plans to introduce a DRM until it is clear that circumstances require it. 


\section{References}

Abbott, M. (2002), 'Completing the introduction of competition into the Australian electricity industry', Economic Papers, Vol. 21, pp.1-13.

Australian Energy Market Commission: AEMC. (2014), National Electricity Amendment (Distribution Network Pricing Arrangements) Rule 2014, AEMC Publication, Sydney.

Australian Energy Market Commission: AEMC. (2012), Power of choice review - giving consumers options in the way they use electricity, AEMC Publication, Sydney.

Australian Energy Market Operator: AEMO. (2014), 2014 Statement of Opportunities, AEMO Publication, Sydney.

Australian Energy Market Operator: AEMO (2013), Demand response mechanism and ancillary services unbundling - detailed design, AEMO Publication, Sydney.

Australian Energy Regulator: AER (2013), State of the energy market, AER Publication, Melbourne.

Aggarwal, S. and Harvey, H. (2013), 'Rethinking Policy to Deliver a Clean Energy Future', The Electricity Journal, Vol. 26, No. 8, pp. 7-22.

Beder, S. (2012). 'The real cause of electricity price rises in NSW', The Conversation, 3 September.

Beder, S. (2003), Power Play: The Fight for Control of the World's Electricity, Melbourne, Scribe.

Borlick. R. (2011), 'Paying for demand-side response at the wholesale level: The small consumers' perspective', The Electricity Journal, Vol. 24, No. 9, pp. 8-19.

Bushnell, J., Hobbs, B. and Wolak, F, (2009), 'When It Comes to Demand Response, is FERC Its Own Worst Enemy?', Staff General Research Papers, Iowa State University, Department of Economics.

Chester, L. (2006), 'The conundrums facing Australia's national electricity market', Economic Papers, Vol. 25, No. 3, pp. 62-77.

Department of Environment. (2014), Quarterly Update of Australia's National Greenhouse Gas Inventory: June 2014, Department of Environment Publication, Canberra.

Energex. (2014a), Energex Tariff Schedule: 1 July 2014 to 30 June 2015, Energex Publication, Brisbane.

Energex. (2014b), Energex Residential and Small Business Tariff Strategy: Retail Discussion Paper, Energex Publication, Brisbane.

Energy Supply Association of Australia: esaa. (2008), Electricity Gas Australia, esaa Publication, Melbourne.

Edenhofer, O., Hirth, L., Knopf, B., Pahle, M., Schlömer, S., Schmid, E., and Ueckerdt, F. (2013), 'On the economics of renewable energy sources', Energy Economics, Vol. 40, Supplement 1, pp. S12-S23. 
Faruqui, A. and Sergici, S. (2013), 'Arcturus: International Evidence on Dynamic Pricing', The Electricity Journal, Vol. 26, No. 7, pp. 55-65.

Grattan Institute. (2014), Fair pricing for power, Grattan Institute Publication, Melbourne.

Hilmer, F. Rayner, M. and Taperell, G. (1993), National Competition Policy, Commonwealth Government Publication, Canberra.

IEA: International Energy Agency. (2005), Energy Policies of IEA Countries - Australia 2005 Review, IEA Publication, Paris. Available at http://www.iea.org/textbase/nppdf/free/2005/australia2005.pdf

Joskow, P. (2006), 'Markets for power in the United States: an interim assessment', The Energy Journal, Vol. 27, No. 1, pp. 1-36.

Masiello, R., Harrison, J. and Mukerji, R. (2013), 'Market Dynamics of Integrating Demand Response into Wholesale Energy Markets', The Electricity Journal, Vol. 26, No. 6, pp. 8-19.

Memery, C. and Kuiper, G. (2014), 'Demand response mechanism: It's a no brainer', On the Wire: CALC Newsletter, No.42, December 2014.

Nelson, T. and Simshauser, P. (2014), 'Metering and the principal-agent problem in restructured energy markets', Vol. 44, No. 2, pp. 169-183.

Nelson, T., Reid, C. and McNeill, J. (2014), 'Energy-only markets and renewable energy targets: complementary policy or policy collision', AGL Applied Economic and Policy Research Working Paper Series, No. 43.

Nelson, T. and Orton, F. (2013), 'A new approach to congestion pricing in electricity markets: Improving user pays pricing incentives’, Energy Economics, Vol. 40, pp. 1-7.

Nelson, T., Nelson, J., Ariyaratnam, J. and Camroux, S. (2013), "An analysis of Australia's Large Scale Renewable Energy Target: restoring market confidence”, Energy Policy, Vol. 62, pp. 386400.

Oakley Greenwood. (2014), 'Cost/benefit assessment of the DRM', Presentation to Stakeholders October 2014, Available at: https://scer.govspace.gov.au/files/2014/11/StakeholdersPresentation-DRM-October-31st.pdf, Accessed online on 19 November 2014.

Parer, W. (2002), Towards a truly national and efficient energy market, Commonwealth Government Publication, Canberra.

Pollitt, M. and Haney, A. (2013), 'Dismantling a competitive retail Electricity Market: Residential Market Reforms in Great Britain, Volume 27, Issue 1, January-February 2014, Pages $66-73$

Quiggin, J. (2014), Electricity privatisation: a record of failure, Report to the Electrical Trades Union, Brisbane.

Quiggin, J. (1997), 'Estimating the benefits of Hilmer and related reforms', Australian Economic Review, Vol. 30, No. 3, pp. 256-72. 
Saddler, H. (2013), 'Power Down: Why is electricity consumption decreasing', Australia Institute Paper, No. 14.

Simshauser, P. and Nelson, T. (2014), 'The Consequences of Retail Electricity Price Rises: Rethinking Customer Hardship', Australian Economic Review, Vol. 47, No. 1, pp. 13-43.

Simshauser, P. and Nelson, T. (2013), 'The Outlook for Residential Electricity Prices in Australia's National Electricity Market in 2020', The Electricity Journal, Vol. 26, No. 4, pp. 6683.

Simshauser, P., Nelson, T., and Doan, T. (2011), 'The boomerang paradox, part II: policy prescriptions for reducing fuel poverty in Australia', The Electricity Journal, Vol. 24, No. 2, pp. 63-75.

Simshauser, P. (2014) 'From first place to last: Australia's policy-induced energy market death spiral', Australian Economic Review, Forthcoming.

Simshauser, P. and Downer, D. (2012). "Dynamic Pricing and the Peak Electricity Load Problem”, The Australian Economic Review, Vol. 45, No. 3, pp. 305-324.

Simshauser, P. (2010), 'Vertical integration, credit ratings and retail price settings in energy-only markets: Navigating the Resource Adequacy problem,' Energy Policy, Vol. 38, No. 11, pp. 74277441.

Simshauser, P. (2008), 'The Dynamic Efficiency Gains from Introducing Capacity Payments in the National Electricity Market', The Australian Economic Review, Vol. 41, No. 4, pp. 349-70.

Sioshansi, F. (2015), EEnergy Informer: The International Energy Newsletter, March 2015, Vol. 25, No. 3.

Van Horn, K. and Gross, G. (2013), 'Demand Response Resources Are Not All They're Made Out to Be: The Payback Effects Severely Reduce the Reported DRR Economic and Emission Benefits', The Electricity Journal, Vol. 26, No. 7, pp. 86-97. 
Appendix 1 - Half-hourly pricing in NEM jurisdictions (1999 -2014)

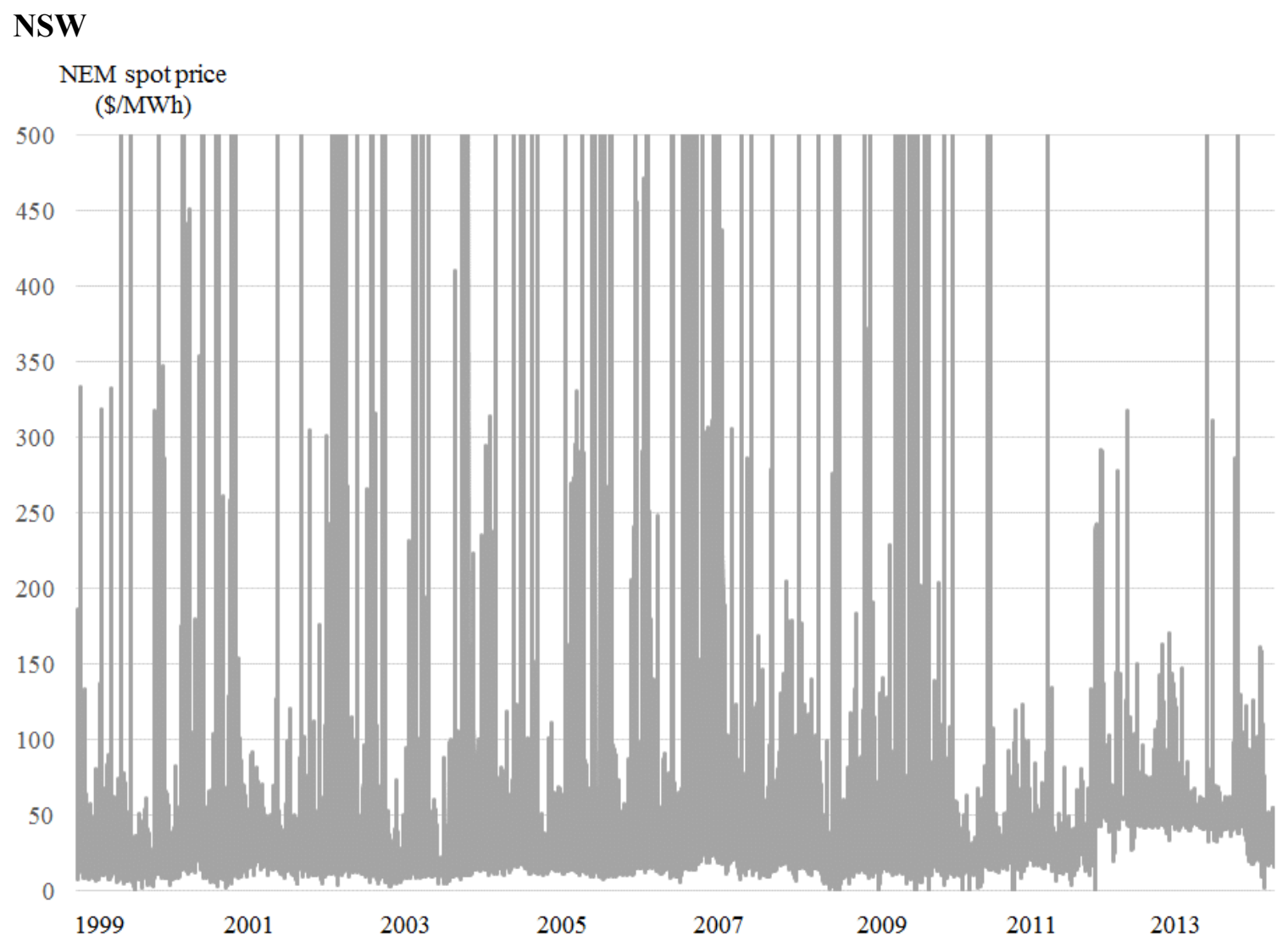

\section{QLD}

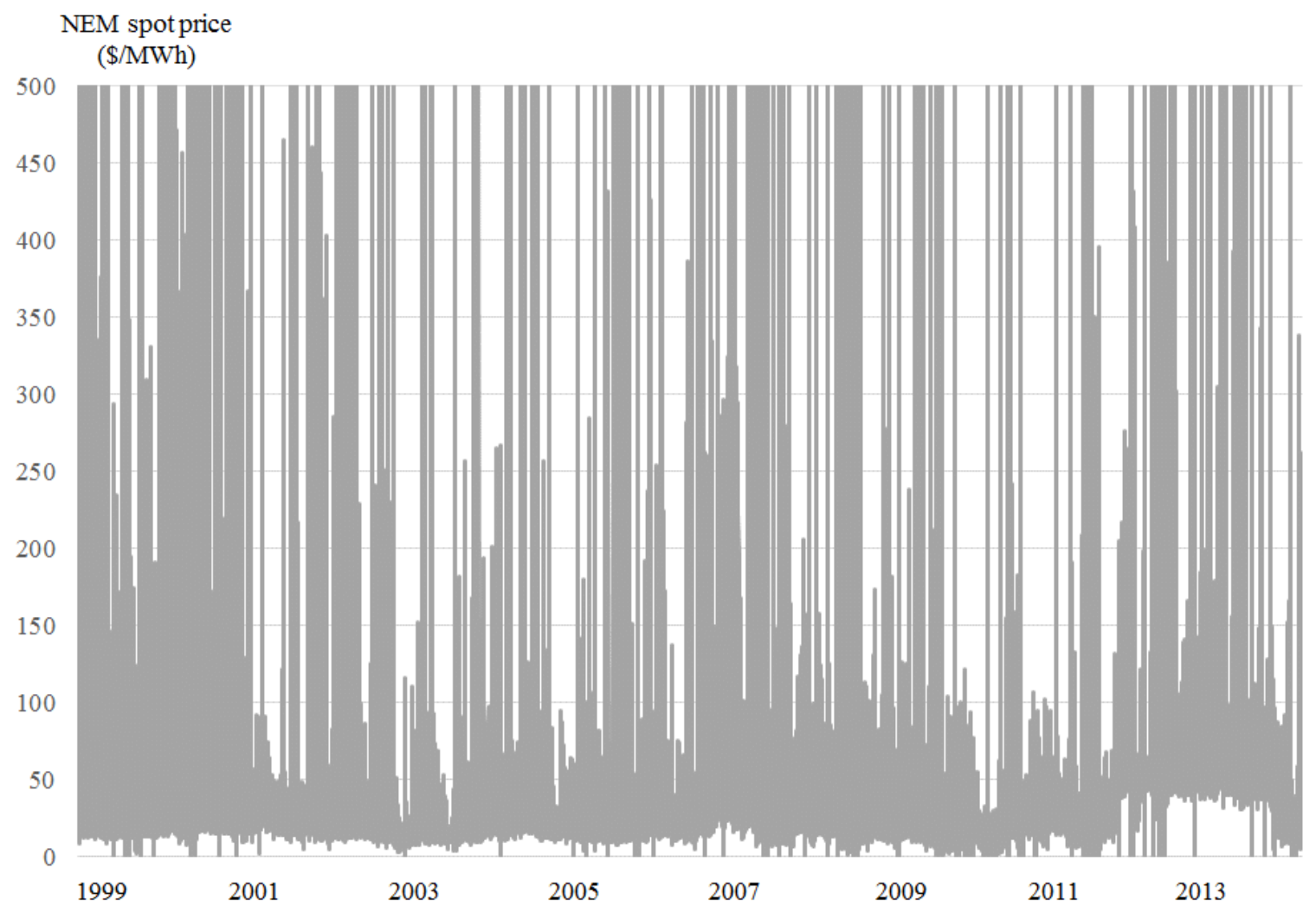




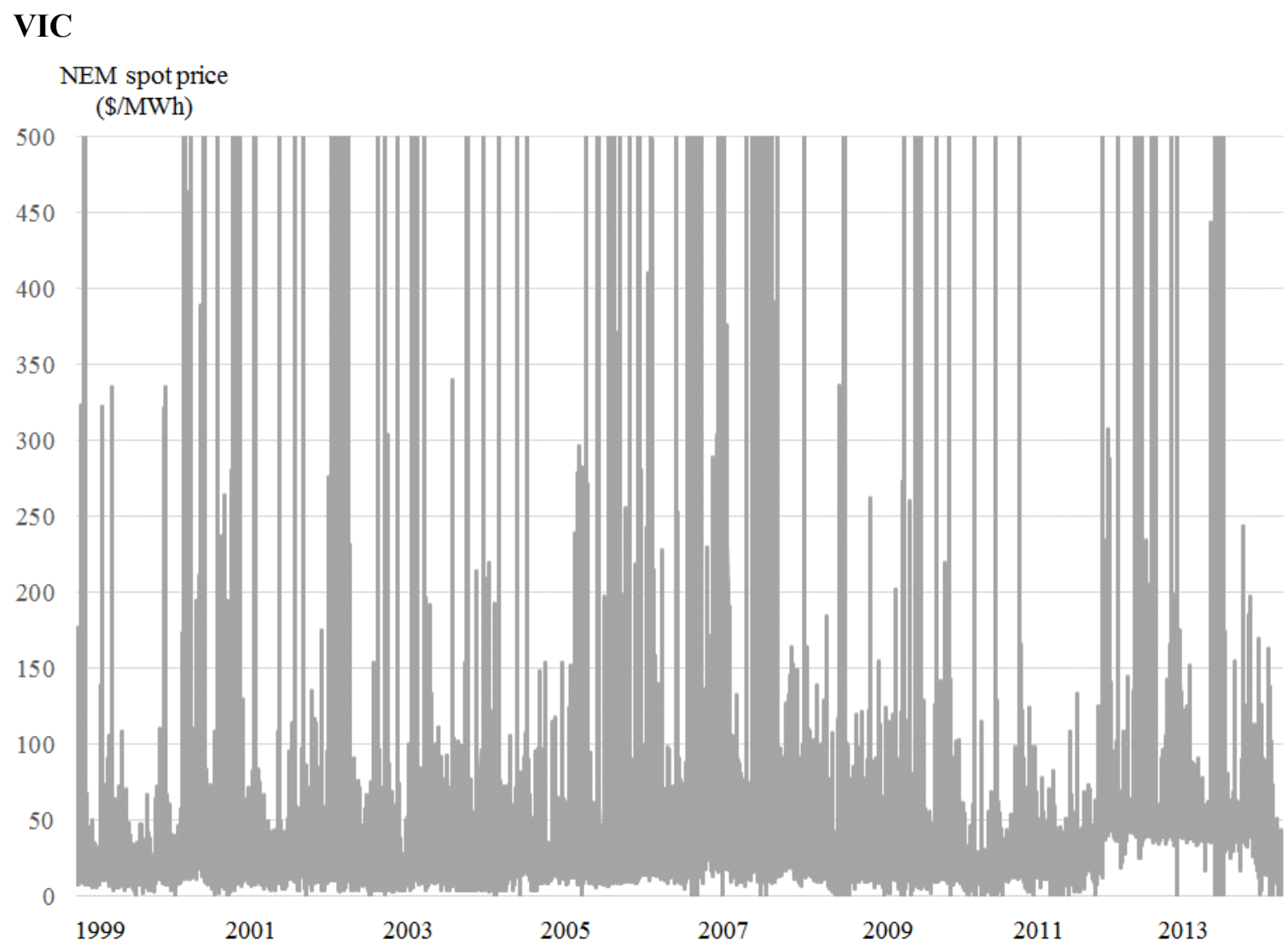

SA

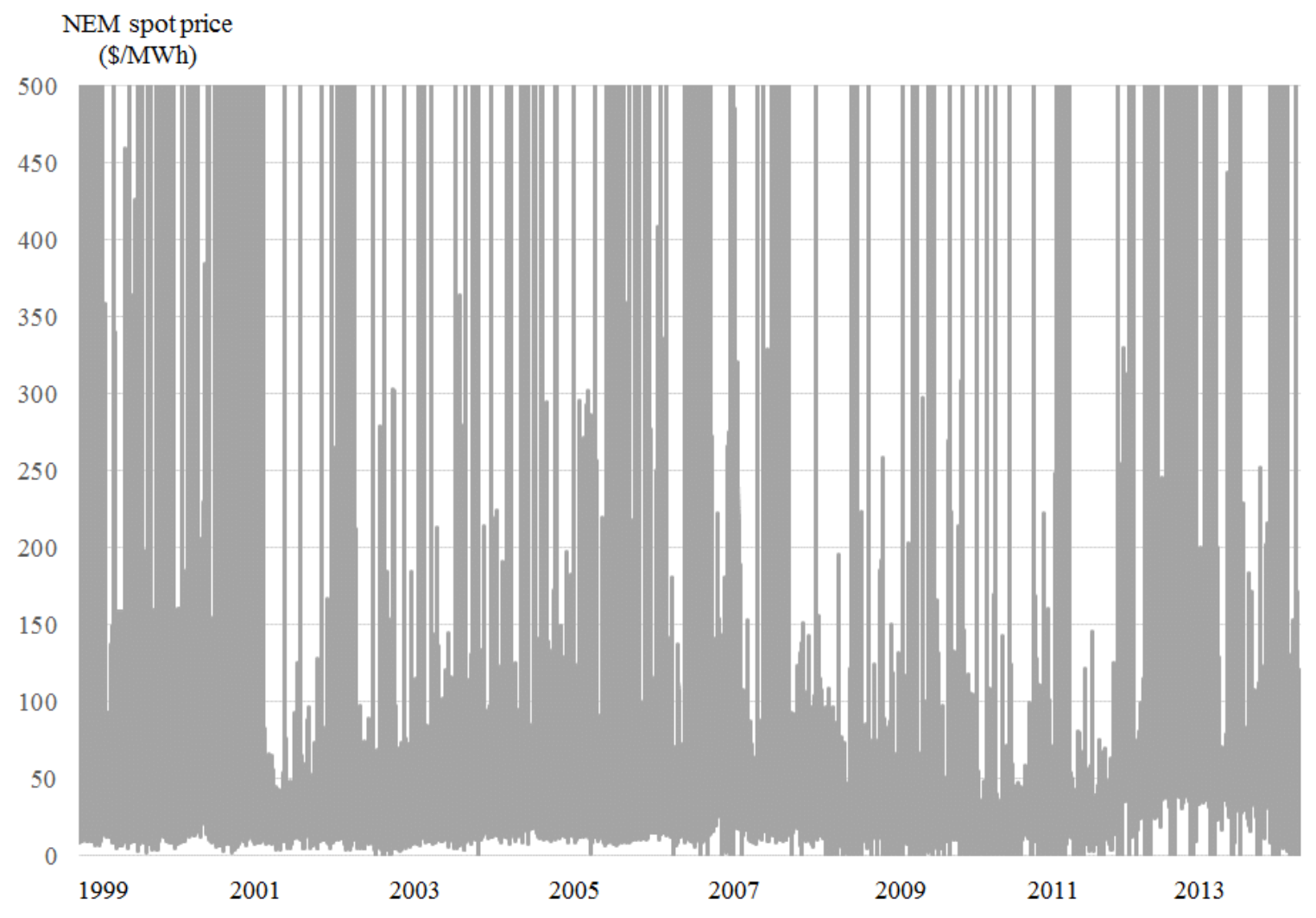




\section{Appendix 2 - Cap contract pricing and turnover}

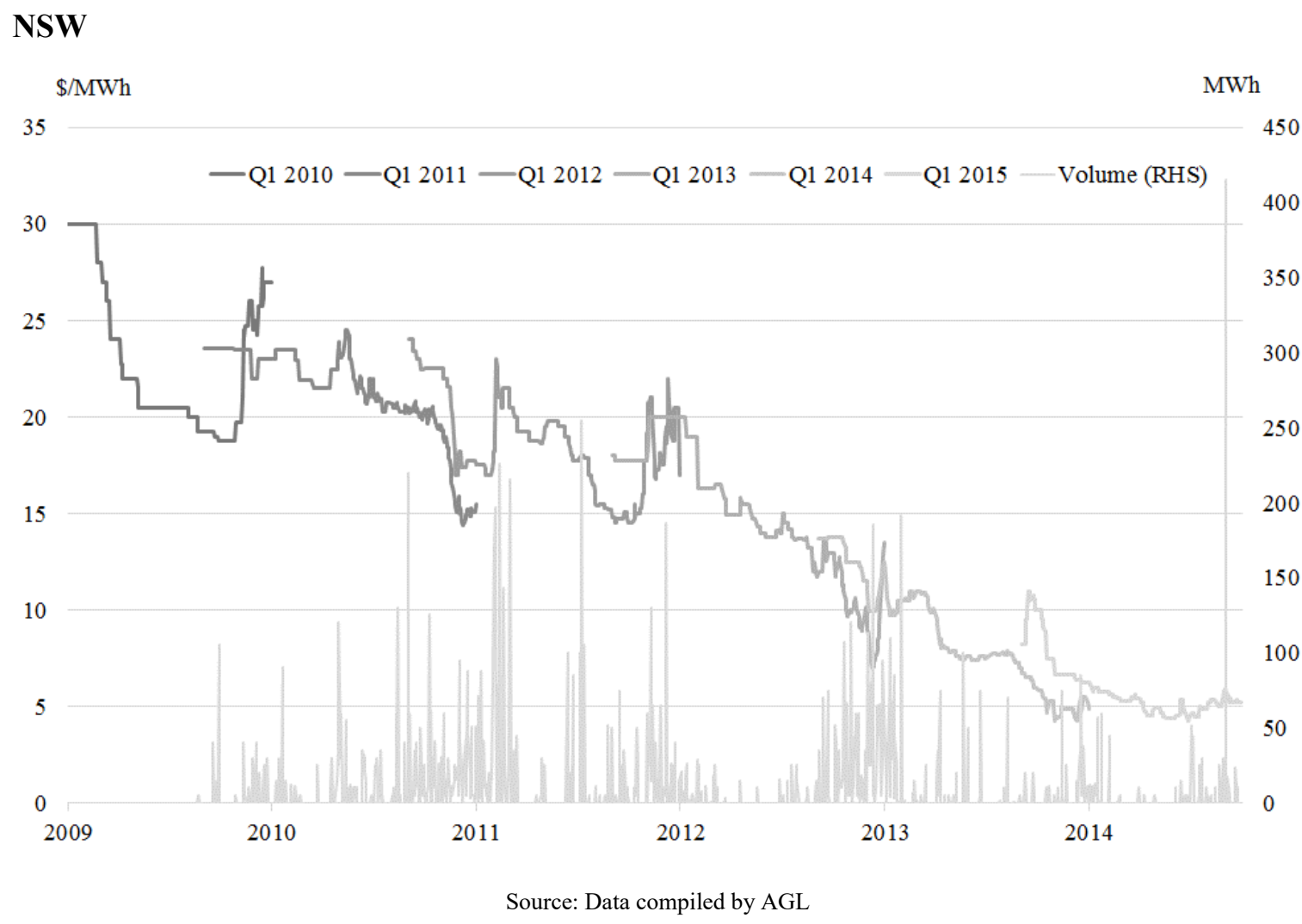

SA

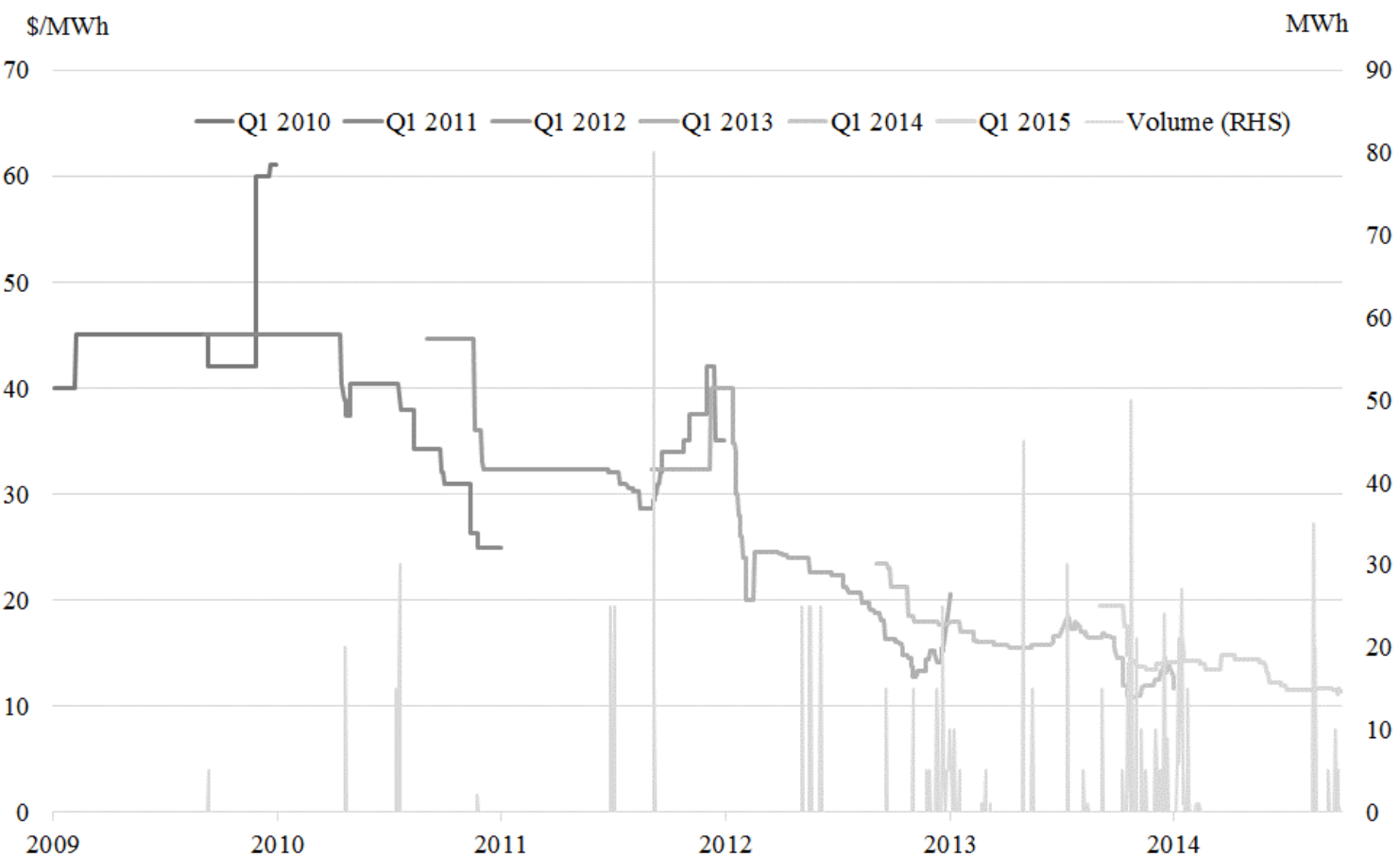

Source: Data compiled by AGL 
VIC

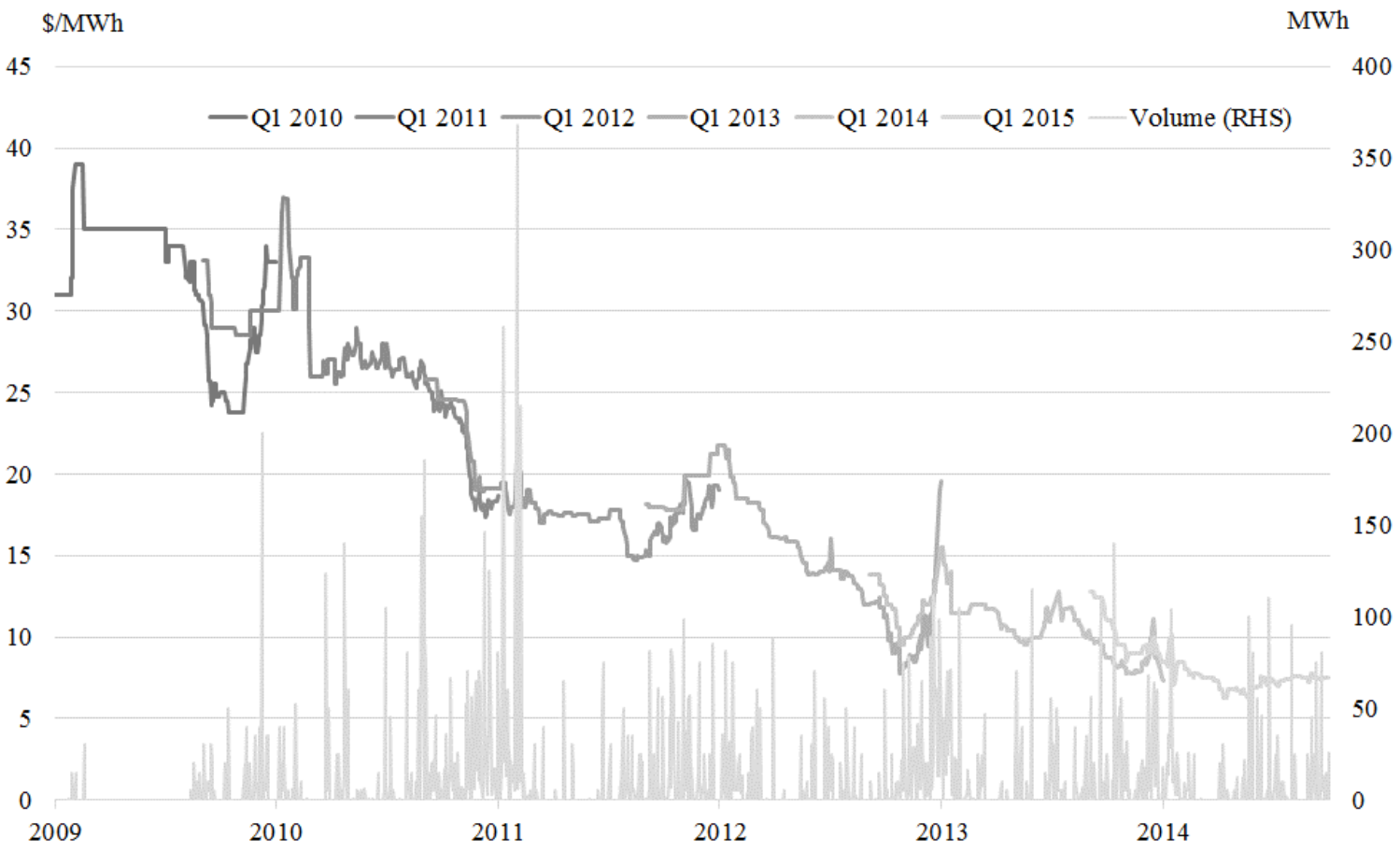

Source: Data compiled by AGL

\section{QLD}

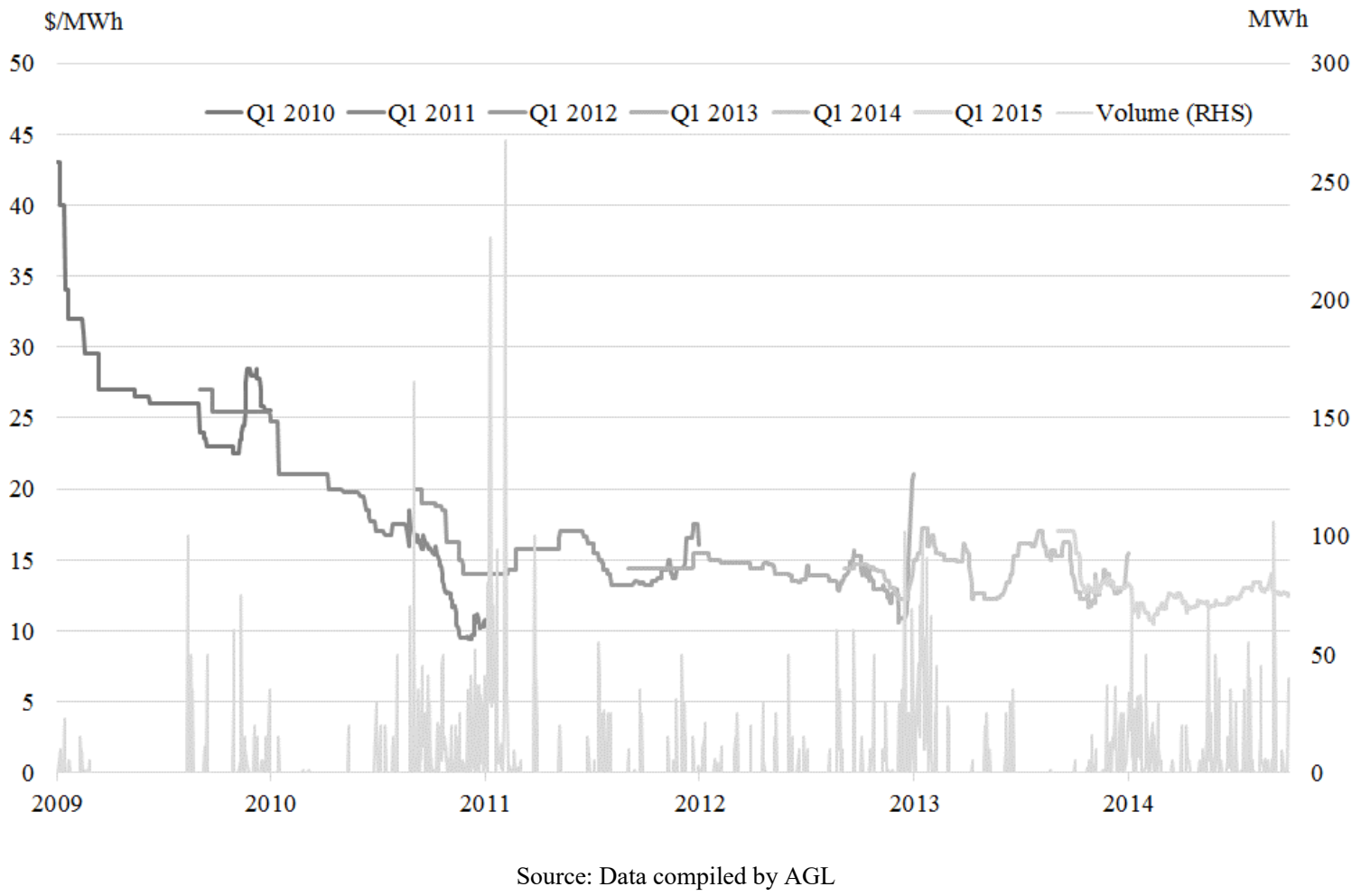

